\title{
The NMDA Glycine Site Antagonist (+)-HA-966 Selectively Regulates Conditioned Stress-induced Metabolic Activation of the Mesoprefrontal Cortical Dopamine but Not Serotonin Systems: A Behavioral, Neuroendocrine, and Neurochemical Study in the Rat
}

\author{
L. E. Goldstein, A. M. Rasmusson, B. S. Bunney, and R. H. Roth \\ Interdepartmental Program in the Neurosciences, The Child Study Center, and Departments of Psychiatry and \\ Pharmacology, Yale University School of Medicine, New Haven, Connecticut 06510
}

Animals confronting threatening stimuli respond with a coordinated set of autonomic, neuroendocrine, neurochemical, and behavioral responses that constitute the stress response. The role of the NMDA receptor and its glycine modulatory site was investigated in a rat conditioned stress model. Behavioral, neuroendocrine, and neurochemical analyses were conducted. Regional dopamine (DA) and serotonin (5HT) utilization was assessed by postmortem tissue measurements of metabolite-to-parent neurotransmitter ratios. Rats were conditioned to fear a tone previously paired with footshock. The following day, rats were systemically administered saline or the NMDA glycine site antagonist $(+)-\mathrm{HA}$ 966 before exposure to thirty minutes of conditioned stress. Conditioned stress resulted in a selective increase in medial prefrontal cortical DA and 5-HT utilization, elevation in serum corticosterone, and freezing behavior in control animals. The conditioned stress-induced increase in DA utilization in control animals was also detected in the lateral prefrontal cortex and nucleus accumbens, whereas DA utilization was not affected in the perirhinal or cingulate cortices, lateral-basolateral amygdaloid complex, anterior ventromedial caudatoputamen, or posterior dorsolateral caudatoputamen. Pretreatment with (+)-HA-966 at $15 \mathrm{mg} / \mathrm{kg}$ completely abolished the conditioned-stress-induced increase in DA utilization in the medial and lateral prefrontal cortices. This effect was regionally specific since $(+)-H A-966$ pretreatment did not block increased DA utilization in the nucleus accumbens. This effect was also neurochemically specific since the stress-induced increase in 5-HT utilization in the medial prefrontal cortex was not affected by (+)-HA-966 pretreatment. Pretreatment with (+)-HA-966 did not affect stressinduced serum corticosterone elevation but did attenuate the freezing response. Control experiments demonstrated that (+)-HA-966 pretreatment did not (1) induce sedation, (2) interfere with habituation to a novel environment, (3) alter

\footnotetext{
Received July 6, 1993; revised Jan. 24, 1994; accepted Feb. 17, 1994.

We thank Drs. W.-X. Shi, P. Shepard, A. Deutch, and B. Moghaddam for helpful comments on the manuscript. We also thank L. Chasney for her help in preparation of the manuscript. This work was supported by USPHS Grants MH14092 and MH28849 and March of Dimes Grant FY93-0521.

Correspondence should be addressed to Robert Roth, Ph.D., Department of Pharmacology, Yale University School of Medicine, 333 Cedar Street, SHM-B256, New Haven, CT 06510.

Copyright (C) 1994 Society for Neuroscience $0270-6474 / 94 / 144937-14 \$ 05.00 / 0$
}

basal DA, 5-HT, or serum corticosterone levels, or (4) block acquisition of aversive memories. These data suggest that the NMDA receptor complex and associated glycine modulatory site may play an important role in the afferent control of the mesoprefrontal cortical DA system during conditioned stress. The relevance of these findings to schizophrenia and human anxiety disorders such as post-traumatic stress disorder are discussed.

[Key words: dopamine, 5-HT, NMDA, glycine site, (+)-HA966, prefrontal cortex, freezing, ultrasonic vocalization, corticosterone, conditioned fear, stress, schizophrenia, posttraumatic stress disorder]

Animals confronting threatening situations react in complex, highly coordinated patterns termed defense reactions or the stress response. This response functions in the natural environment to maximize survival in the face of predatory threat (Fanselow, 1984) and includes increased vigilance, enhanced reactivity to environmental stimuli, increased autonomic reactivity, alterations in cardiovascular functioning, and activation of neuroendocrine responses. In the rat, behavioral reactions to stress also include cessation of ongoing behavior, characteristic changes in respiration, freezing, and ultrasonic vocalization (Sewell, 1967; Blanchard and Blanchard, 1969; Bouton and Bolles, 1980; Fokkema et al., 1986). Many of the behavioral, neuroendocrine, autonomic, and neurochemical changes associated with the stress response have been evolutionarily conserved and are found in most mammals, including humans. Psychophysiological similarities in the stress response across mammalian species may reflect common neurobiological processes underlying the emotional states of fear in animals and anxiety in humans (Charney et al., 1993).

Exposure to threatening stimuli is also known to activate monoaminergic systems in the CNS (Rubin et al., 1970; Maas et al., 1971; Thierry et al., 1976; Deutch and Roth, 1990; Inoue et al., 1993). Acute inescapable footshock in rodents results in increased dopamine (DA) utilization in the medial prefrontal cortex (m-PFC) as measured by ex vivo tissue analysis (Thierry it al., 1976; Herman et al., 1982; Roth et al. 1988) and in vivo microdialysis (Abercrombie et al., 1989; Sorg and Kalivas, 1993). In the rat, unconditioned stress, such as spatial proximity to other rats exposed to footshock (Kaneyuki et al., 1991), or conditioned stress (Herman et al., 1982; Deutch et al., 1985) such as exposure to an environmental context previously paired with 
footshock, are known to robustly activate the mesoprefrontal cortical DA system. More substantial or prolonged exposure to stress results in recruitment of DA systems that innervate regions such as the nucleus accumbens scpti and striatum (Roth et al., 1988).

The effect of stress on the 5-HT system has been less rigorously studied. Footshock was first shown to elevate 5-HT turnover in whole brain and to activate 5-HT metabolism in cortex (Bliss et al., 1968; Thierry et al., 1968). Since then a variety of unconditioned stressors have been shown to increase 5-HT utilization in the frontal cortex of rats and mice (Adell et al., 1988; Dunn, 1988; Miyauchi et al., 1988; Pei et al., 1990; Dunn and Welch, 1991; Heinsbroek et al., 1991). In addition, reexposure to a context previously paired with intense footshock has recently been shown to increase 5-HT metabolism in the m-PFC (Inoue et al., 1993).

Control of the mesoprefrontal cortical DA system is complex and involves interaction between a variety of neuroactive peptides and monoamines, as well as excitatory and inhibitory amino acids (Deutch and Roth, 1990; Kalivas, 1993). Recent studies have demonstrated that excitatory amino acids may be involved in the selective metabolic activation of subsets of DA neurons within the ventral tegmental area (VTA) that project to the m-PFC (Kalivas et al., 1989). Indeed, receptors for excitatory amino acids are found in the VTA (Monaghan and Cotman, 1985).

The NMDA receptor complex is an excitatory amino acid ligand-gated ion channel that is selectively activated by NMDA and regulated at several pharmacologically distinct sites (Collingridge and Lester, 1989). One of these sites is a high-affinity, strychnine-insensitive glycine binding site that is found in many regions of the mammalian brain (Bristow et al., 1986). Competitive antagonists of the strychnine-insensitive glycine site that cross the blood-brain barrier have become available, making possible in vivo pharmacological manipulation of the NMDA receptor through this regulatory site. One such high-affinity, selective antagonist at the NMDA receptor glycine site is $(+)$ HA-966, the recently resolved enantiomer of the drug (+)-3amino-1-hydroxy-2-pyrrolidinone (Singh et al., 1990). In the rat, systemic administration of this compound has been shown to normalize DA neuron firing (McMillen et al., 1992; Shepard and Lehmann, 1992). Previous work in this laboratory has also demonstrated that systemic and intra-VTA administration of (+)-HA-966 blocks physical restraint-induced increases in DA utilization in the m-PFC of the rat (Morrow et al., 1993).

In the present study, a nonsedating systemic dose of $(+)$-HA966 was tested for its effects on the behavioral, neuroendocrine, and neurochemical responses induced in the rat by conditioned psychological stress. We examined its effects on dopaminergic and serotonergic responses in a variety of cortical, limbic, and striatal terminal regions. Since the NMDA receptor complex has been implicated in memory processing (e.g., Morris et al., 1986; Miserendino et al., 1990), we also tested the effect of pretraining administration of this compound on acquisition of the behavioral, neuroendocrine, and neurochemical responses to conditioned stress.

\section{Materials and Methods}

Animals and housing conditions. All procedures met guidelines and protocols approved by the Yale Animal Care and Use Committee. Male albino Sprague-Dawley rats (Camm, Wayne, NJ) weighing 300-400 gm were used. All rats were individually caged and acclimated in this laboratory's animal colony room for at least 2 weeks prior to experimentation. Rats were maintained on a 12:12 hr light-dark schedule with lights on at 1500 . Food and water were available ad libitum. Contact with human personnel was limited to a single attendant.

Apparatus. Testing was conducted in the dark in a modified standard Plexiglas and aluminum conditioning chamber isolated in a sound attenuation cubicle. In order to avoid contamination of the test chamber with olfactory cues, all surfaces of the chamber were extensively washed with $70 \%$ ethanol and fan dried after each animal exposure. An infrared television camera (Sanyo Electronics) and infrared illuminator were positioned over the test cage and connected to a standard televisionvideo recording system located in a monitoring station in the next room. This setup allowed remote monitoring and recording of test subjects in complete darkness. The top of the testing chamber was constructed of transparent Plexiglas into that was inserted a miniature narrow-bandwidth ultrasound microphone (Panasonic, Tokyo, Japan) with a center frequency of $21 \mathrm{kHz}$, the same frequency utilized by adult rats for distress vocalization (Sewell, 1967). The signal from the ultrasound microphone was fed to an amplifier in the monitoring room where it was filtered, digitized (sampling frequency, $15 \mathrm{~Hz}$ ), and analyzed by a computer programmed to measure number, duration, and amplitude of the ultrasonic calls. Shock intensity was measured by a digital oscilloscope running in the differential mode with a $1 \mathrm{k} \Omega$ load in series with a $100 \mathrm{k} \Omega$ resistor bridge across adjacent cage bars. Current was defined as the root mean square voltage across the $1 \mathrm{k} \Omega$ resistor $(\mathrm{mA}=0.707$ $\times 0.5 \times$ peak-to-peak voltage). Shock intensity was set at $0.40 \mathrm{~mA}$. Shock duration was $0.5 \mathrm{sec}$.

Drugs. (+)-HA-966 was provided by Research Biochemicals, Inc. (Natick, MA) under the National Institute of Mental Health Funded Synthesis Program. Solutions of (+)-HA-966 were freshly prepared before use with sterile normal saline.

Preliminary test of drug-Induced sedation. Previous studies in this laboratory using (+)-HA-966 at an intraperitoneal dose of $15 \mathrm{mg} / \mathrm{kg}$ suggested that this dose does not produce sedation in rats (L. Goldstein, unpublished observations). This dose was then more closely examined for sedative effects. Rats were pretreated with either saline $(1 \mathrm{ml} / \mathrm{kg}$, i.p.) or (+)-HA-966 $(15 \mathrm{mg} / \mathrm{kg}$ at $1 \mathrm{ml} / \mathrm{kg}$, i.p.) $15 \mathrm{~min}$ before introduction into a novel, dark, sound-attenuating test chamber equipped with an eight cage computer-assisted activity monitoring system $(\mathrm{Om}-$ nitech Digiscan, Columbus, $\mathrm{OH}$ ). Test subjects were allowed to freely explore the novel chambers for two consecutive 30 min periods. Ambulation was continuously monitored by infrared photobeam interruption and analyzed by computer. Cumulative locomolor activity was compiled into two successive 30 min test intervals.

Conditioning and testing procedures. All studies were conducted in the dark during the active phase of the rat diurnal activity cycle, beginning $1-6 \mathrm{hr}$ after dark onset. The rationale for testing in the dark was to approximate the psychophysiological conditions when these nocturnal animals are most likely to encounter threatening stimuli under natural conditions. The experimental model used in this study is schematically presented in Figure 1. To test the effect of (+)-HA-966 pretreatment on the expression of conditioned stress, all subjects were injected with saline $(1 \mathrm{ml} / \mathrm{kg}$, i.p.) $15 \mathrm{~min}$ prior to testing on day 1 , and returned to their home cages (Fig. 1A). Test animals were then introduced into the dark test chamber and allowed to explore freely the cage for thirty minutes to facilitate habituation to the chamber. During the last 5 min of this habituation period, three $5 \mathrm{sec} 56 \mathrm{~dB}$ white noise tones were presented by computer. Immediately following, a $30 \mathrm{~min}$ conditioning period was initiated. During conditioning, the animals were randomly presented with ten $5 \mathrm{sec}$ white noise tones (conditioned stimulus, CS) that coterminated with a $0.5 \mathrm{sec} 0.4 \mathrm{~mA}$ footshock (unconditioned stimulus, US). At the conclusion of the conditioning period, the subjects were returned to their home cages. Unstressed, nonshocked control animals were treated as above except that these animals did not receive footshock (US) during the conditioning period. The next day, subjects in the conditioned stress groups were injected with either saline (1 ml/kg, i.p.) (SAL-CS group), or (+)-HA-966 $(15 \mathrm{mg} / \mathrm{kg}$ at $1 \mathrm{ml} / \mathrm{kg}$, i.p.) (HA-CS group) 15 min before behavioral testing. Animals in the nonshocked control group (SAL-NS group) were injected with saline (1 $\mathrm{ml} / \mathrm{kg}$, i.p.) $15 \mathrm{~min}$ prior to behavioral testing. The animals were then reintroduced into the testing chamber. During this extinction trial, animals in all groups were randomly presented with ten $56 \mathrm{~dB}$ white noise tones without footshock. To test the effects of $(+)$-HA-966 on the acquisition of conditioned stress, rats were tested as described above, but 


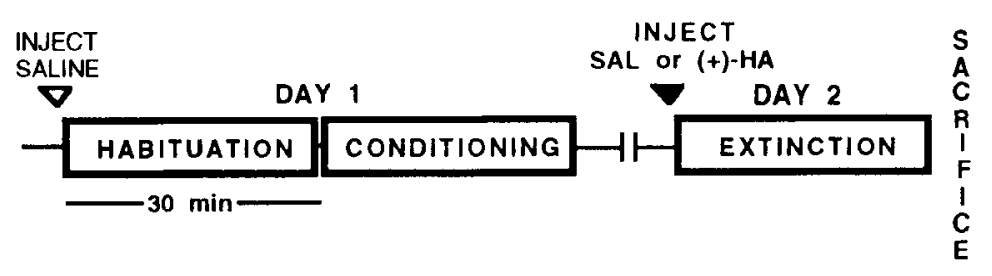

B

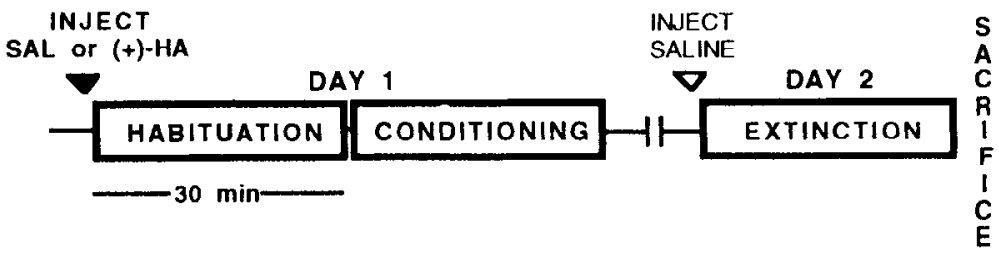

Figure 1. Experimental models. $A$ shows conditioned stress model used to test the effect of systemic administration of (+)-HA-966 (15 mg/kg, i.p.) on the expression phase of conditioned stress. Injection of $(+)$-HA-966 or saline is given $15 \mathrm{~min}$ before beginning the extinction period on day 2. $B$ shows conditioned stress model used to test the effect of systemic administration of (+)-HA-966 (15 mg/kg, i.p.) on the acquisition phase of conditioned stress. Pretraining injection of $(+)$-HA-966 or saline is given $15 \mathrm{~min}$ before beginning the habituation period on day 1 . were given either saline or (+)-HA-966 15 min before training on day 1. All animals were given saline before testing on day 2 (Fig. $1 B$ ).

At the conclusion of the testing period on day 2 , the animals were rapidly decapitated. Anesthesia prior to death was not used due to possible interference with neurochemical and neuroendocrine measurements. Trunk blood was collected for determination of serum corticosterone levels and brain tissue was obtained for neurochemical analyses as described below.

A separate group of animals was used for determination of basal neurochemical and serum corticosterone levels. These animals were injected with either saline ( $1 \mathrm{ml} / \mathrm{kg}$, i.p.) or (+)-HA-966 (15 mg/kg, i.p.) and returned to their home cages in the colony facility for $45 \mathrm{~min}$. This time period corresponds to the time from injection to death in animals tested in the behavioral studies. After this $45 \mathrm{~min}$ period, animals were removed from their home cages and rapidly decapitated as described above.

Behavioral measurements. Behavioral data (freezing, grooming, crossings, and rears) were remotely coded by an observer using an electronic pushbutton/toggle switch assembly connected to a computer by an analog-to-digital converter. Ultrasonic vocalizations were electronically monitored as detailed above and compiled by computer. The following criteria had to be met to qualify as an ultrasonic vocalization: (1) remote behavioral observation of the animal confirmed deep, prolonged respiration at approximately $0.5 \mathrm{~Hz}$ preceded by short, shallow rapid panting at approximately $3-4 \mathrm{~Hz}$ (Frysztak and Neafsey, 1991); (2) call duration was greater than $20 \mathrm{msec}$ but no longer than $3 \mathrm{sec}$ as visualized on a digital oscilloscope; and (3) call tracings appeared on both the oscilloscope and computer monitor screen. Use of these critcria prevented the recording of spurious signals such as those due to animals sniffing or scratching the aluminum sidewalls. Freezing behavior was strictly defined as no visible movement of the animal, including vibrissae, except that related to respiration. This behavior has been used as an index of fear in the rat (Fanselow, 1980; Conti et al., 1990). Freezing was coded by throwing a toggle switch while the animal was engaged in this behavior. This signal was continuously recorded and compiled by computer as the percentage of time the animal froze during each of ten 3 min intervals comprising the 30 min test period. Crossings were coded each time the base of an animal's tail crossed a grid drawn on the video screen and were compiled as the number of such events occurring per $3 \mathrm{~min}$ interval. Rears were counted when an animal simultaneously raised both forepaws off the cage bars and was not otherwise engaged in grooming behavior. Rears werc coded and likewise compiled as the number occurring per $3 \mathrm{~min}$ interval. Animals were initially coded by an observer not blind to the experimental conditions. Video records of 11 randomly selected animals were recoded by an observer blind to the experimental conditions. Statistical analysis showed a high correlation between results generated by unblind and blind behavioral observations (crossings, $r=0.98, p<0.0001$; rearings, $r=$
$0.98, p<0.0001$; freezing, $r=0.99, p<0.0001$ ). Therefore, the initial behavioral results were used for statistical analysis.

Brain dissection and neurvchermical measurements. At the conclusion of behavioral testing animals were rapidly decapitated. The brain was quickly removed from the calvarium, immersed in chilled normal saline $\left(-2.5^{\circ} \mathrm{C}\right)$, and transferred ventral side up to an ice-chilled stainless steel brain mold with precision milled transverse slots. Coronal slices $(2 \mathrm{~mm})$ were rapidly made by insertion of chilled razor blades. The slices were then transferred to a frozen plastic dissection platform filled with a gel coolant that maintained the platform temperature at approximately $1.0^{\circ} \mathrm{C}$. Dissection and punch sites are schematically depicted in Figure 2. Tissue biogenic amines were isolated according to a modification of the procedure of Reinhard and Roth (1982). Briefly, frozen tissue was sonicated in $0.4 \mathrm{ml}$ of $0.1 \mathrm{M}$ perchloric acid containing $8 \mathrm{ng}$ of 3,4dihydroxybenzylamine and $24 \mathrm{ng} N$-methyl-serotonin as internal standards. Samples were sonicated in plastic Eppendorf tubes immersed in a saline and ice slurry to prevent thermal decomposition of the monoamines and their metabolites. Forty microliters of solution was removed for protein measurement by the method of Lowry et al. (1951). The remaining solution was centrifuged under refrigeration for $20 \mathrm{~min}$. Sample supernatants were collected and mixed with $25 \mu \mathrm{l}$ of $3.0 \mathrm{M}$ Tris base $(\mathrm{pH} 11.0)$, resulting in a solution buffered to $\mathrm{pH} 8.6$. This solution was then passed over minicolumns packed with alumina (Aldrich Chemical Co., Milwaukee, WI). The effluents, containing 5-HT and its metabolite, 5-hydroxyindoleacetic acid (5-HIAA), were immediately stored at $-70^{\circ} \mathrm{C}$ until analysis. The alumina minicolumns with adsorbed catechols were then centrifuged, washed with distilled water, and eluted with $150 \mu \mathrm{l}$ of $0.1 \mathrm{M}$ oxalic acid. The eluates containing DA and its metabolite 3,4-dihydroxyphenylacetic acid (DOPAC) were stored at $-70^{\circ} \mathrm{C}$ until analysis. The samples were assayed for monoamines using reversed-phase high-performance liquid chromatography (HPLC) coupled with amperometric electrochemical detection. Separate systems were chromatographically optimized for measurement of DA and DOPAC and for 5-HT and 5-HIAA. Sample aliquots of $50 \mu \mathrm{l}$ were injected onto an HPLC system consisting of (1) a $10 \mathrm{~cm} \times 2.1 \mathrm{~mm}$ narrow-bore column packed in our laboratory with $3 \mu \mathrm{m} \mathrm{C}-18$ packing for DA and DOPAC, or an Altech C-18 Microsorb column (Alltech Associates, Deerfield, IL) for 5-HT and 5-HIAA, and (2) a glassy carbon electrode assembly maintained at $+0.70 \mathrm{~V}$ (vs $\mathrm{Ag} / \mathrm{AgCl}$ reference electrode) coupled with an LC-3 electrochemical detector (Bioanalytical Systems, West Lafayette, IN). The systems were optimized to increase the signal-tonoise ratio by placing a low-pass $\mathrm{RC}$ filter on the recording device. The mobile phase for determination of DA and its metabolite DOPAC consisted of $2-8 \%$ methanol in $0.1 \mathrm{M}$ monobasic sodium phosphate buffer, $0.2 \mathrm{~mm}$ octanesulfonic acid, and $0.1 \mathrm{~mm}$ EDTA, with $\mathrm{pH}$ optimized between 2.7 and 3.2 for acid metabolite detection. The mobile phase for determination of 5-HT and its metabolite 5-HIAA consisted of 0.02 M sodium acetate, $10 \%(\mathrm{v} / \mathrm{v})$ methanol, $0.3 \mathrm{~mm}$ EDTA, and $7.2 \mathrm{~mm}$ 
A
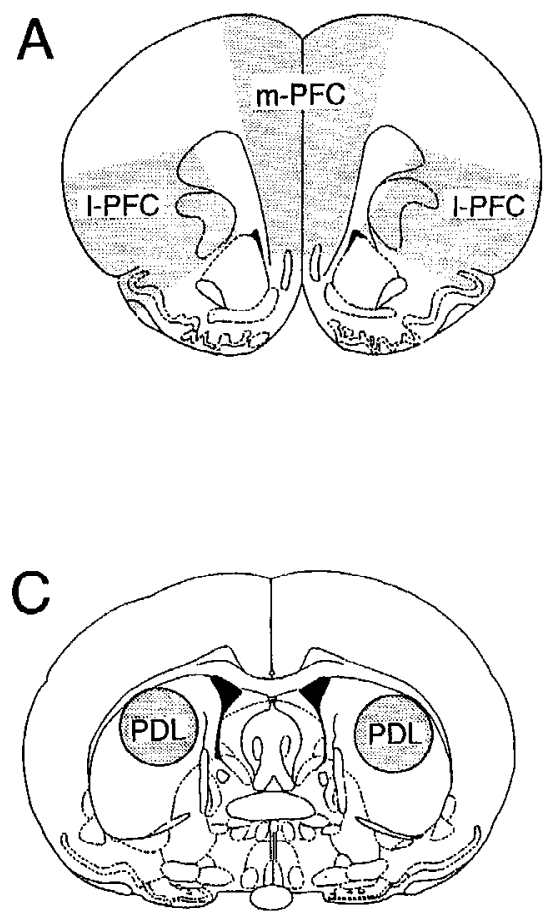
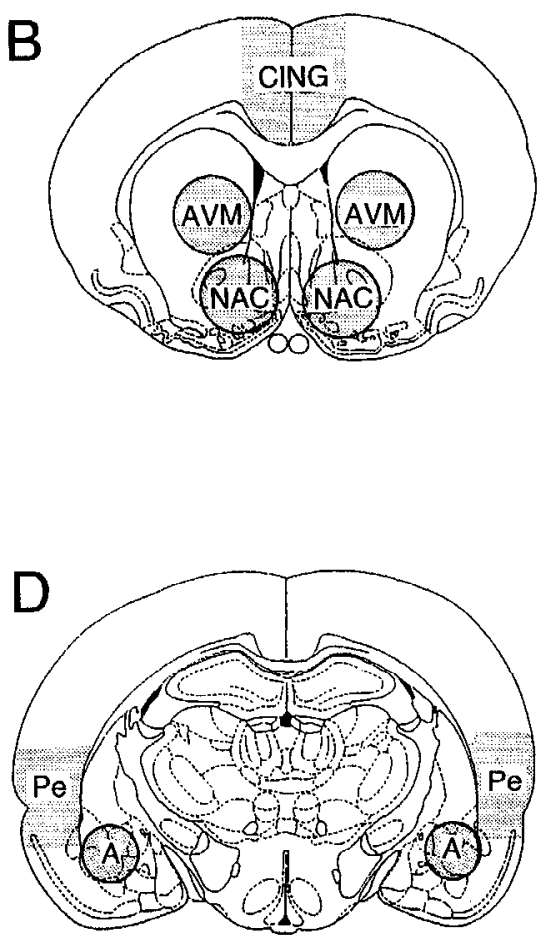

Figure 2. Dissection and punch dialyzed for neurochemical responses to conditioned stress. Bottom panel shows a sagittal section of the rat brain indicating approximate levels at which slices were taken. For convenience of illustration only a single sagittal plane is represented. Letters above lines represent slices that are shown as coronal sections with the same letter designation in the top four panels: $m-P F C$, medial prefrontal cortex: $1-P F C$, lateral prefrontal cortex; $C I N G$, posterior cingulate cortex; $N A C$, nucleus accumbens septi; $A V M$, anterior ventromedial caudatoputamen; $P D L$, posterior dorsolateral caudatoputamen; $P e$, perirhinal cortex; $A$, amygdaloid complex.

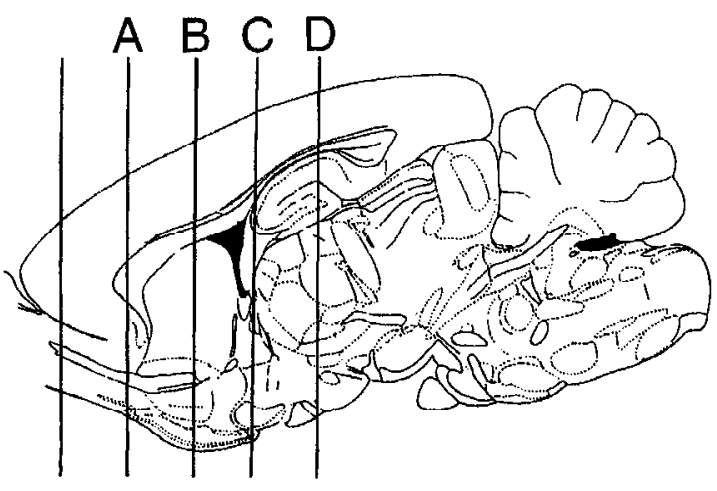

triethylamine, at pH 3.90. Quantitation of biogenic amines and their respective metabolites was achieved by measuring peak heights and comparing them to internal standard values. DA and 5-H T utilization was assessed by calculating the ratio of the acid metabolite to the parent neurotransmitter. The DOPAC:DA and 5-HIAA:5-HT ratios correlate with the net metabolic flux within the tissue sample at the time of death. Some brain regions from some animals were excluded from analysis due to technical difficulties with individual dissections or sample preparation.

Neuroendocrine measurement. Serum corticosterone was measured by a magnetic radioimmunoassay developed in this laboratory. Trunk blood was collected at decapitation in glass tubes and immediately placed on ice prior to centrifugation. Serum was collected and stored at $-70^{\circ} \mathrm{C}$ until it was assayed. Serum samples $(2 \mu 1)$ were diluted in phosphate-buffered saline with gelatin. The radioimmunoassay used a polyclonal rabbit anti-corticosterone primary antibody (kindly provided by Dr. G. Niswinder, Colorado State University), commercially purchased ${ }^{125}$ I-corticosterone (ICN Biomedicals, Inc., Costa Mesa, CA), and a custom-prepared polyclonal goat anti-rabbit IgG secondary antibody conjugated to paramagnetic particles (Corning Diagnostics, Corning, NY). Incubation with the primary antibody was conducted overnight under refrigeration. Incubation with the secondary antibody was conducted at room temperature for $1 \mathrm{hr}$. Bound versus unbound fractions were then separated by placing the test tubes in the presence of a magnetic field. This drew the antibody complexes to the side walls of the tubes. Free labeled corticosterone and antibody were then with- drawn from the test tubes using vigorous suction. Corticosterone levels were determined using a standard gamma counter. Serum counts corrected for nonspecific binding were compared to those obtained on a standard curve of varying known concentrations of corticosterone. Using this procedure, corticosterone levels of $10 \mathrm{ng} / \mathrm{ml}$ in $2 \mu \mathrm{l}$ of serum could be routinely measured.

Statistics. Data were analyzed by analysis of variance for significant differences among all means. The Student-Newman-Keuls post hoc multiple comparison procedure was used for comparison among means where appropriate. Temporal analyses of behavioral data were conducted with a repeated measures analysis of variance model. These analyses were conducted using the SUPERANOVA computer program (Abacus Concepts, Inc., Berkeley, CA). The two-tailed Fisher Exact Probability Test was used for statistical analysis of the effects of treatment on the number of animals vocalizing per group. Data are expressed as means \pm standard error of the mean (SEM). Statistical significance was set at $p<0.05$.

\section{Results}

\section{Test for drug-induced sedation}

No difference in locomotor activity was observed when animals were injected with either saline or $(+)-\mathrm{HA}-966(15 \mathrm{mg} / \mathrm{kg}$, i.p. $)$ $45 \mathrm{~min}$ before introduction into a novel environment (Fig. 3). In addition, the initial burst of ambulatory activity in response 


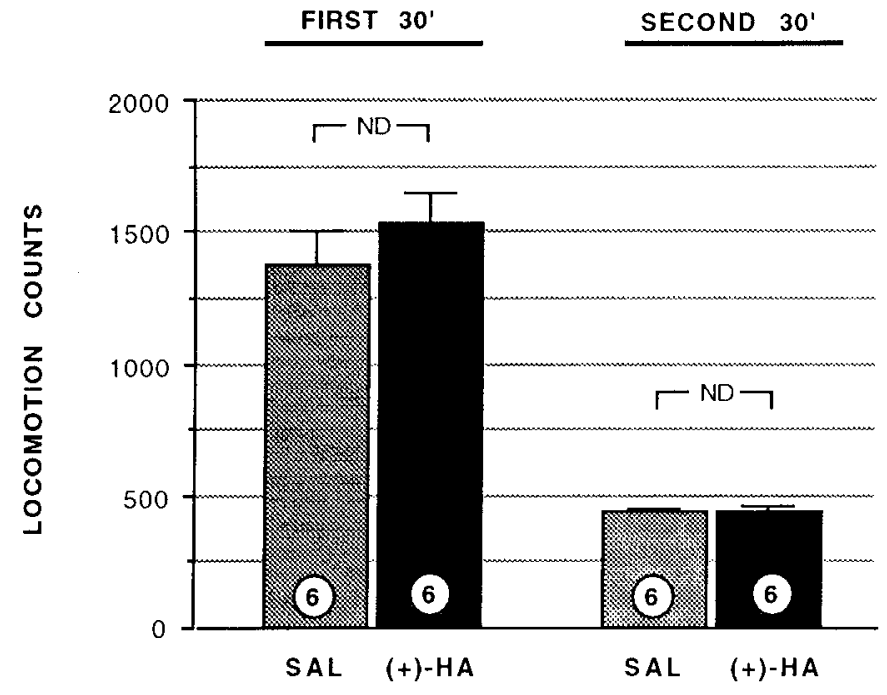

Figure 3. Systemic administration of $(+)-H A-966$ at $15 \mathrm{mg} / \mathrm{kg}$ is nonsedating. Intraperitoneal administration of (+)-HA-966 at $15 \mathrm{mg} / \mathrm{kg} 15$ min before subjects were introduced into a novel dark chamber for 1 hr does not affect novelty-induced locomotor activity. Control animals were injected with saline $(S A L)$. Locomotion was assessed by photobeam interruptions in an activity chamber. The test session was divided into two consecutive 30 min periods. No significant difference was noted between the saline and (+)-HA-966 pretreated groups. However, a significant effect of time was observed $(p<0.0001)$. Numbers in circles at base of histogram bars indicate number of rats in each group.

to a novel environment was similar in both saline and (+)-HA966 pretreated groups. A significant effect of time in the novel environment was detected $[F(1,20)=139.9, p<0.0001]$. No interaction between treatment group and time was detected, indicating a similar pattern of habituation to the test chamber in both the saline and (+)-HA-966 pretreated groups.

\section{Effect of $(+)-H A-966$ on basal serum corticosterone and} neurochemical measures

Dopaminergic and serotonergic neurochemistry and serum corticosterone values in untreated naive rats are shown in Table 1. Note that these rats did not receive injections.

To test whether (+)-HA-966 had effects on basal DA and 5-HT utilization or serum corticosterone concentration, rats were injected with either saline $(1 \mathrm{ml} / \mathrm{kg}$, i.p.) or $(+)-\mathrm{HA}-966$, (15 mg/kg, i.p.) and returned to their home cages for $45 \mathrm{~min}$ before death. This $45 \mathrm{~min}$ period corresponds to the time from

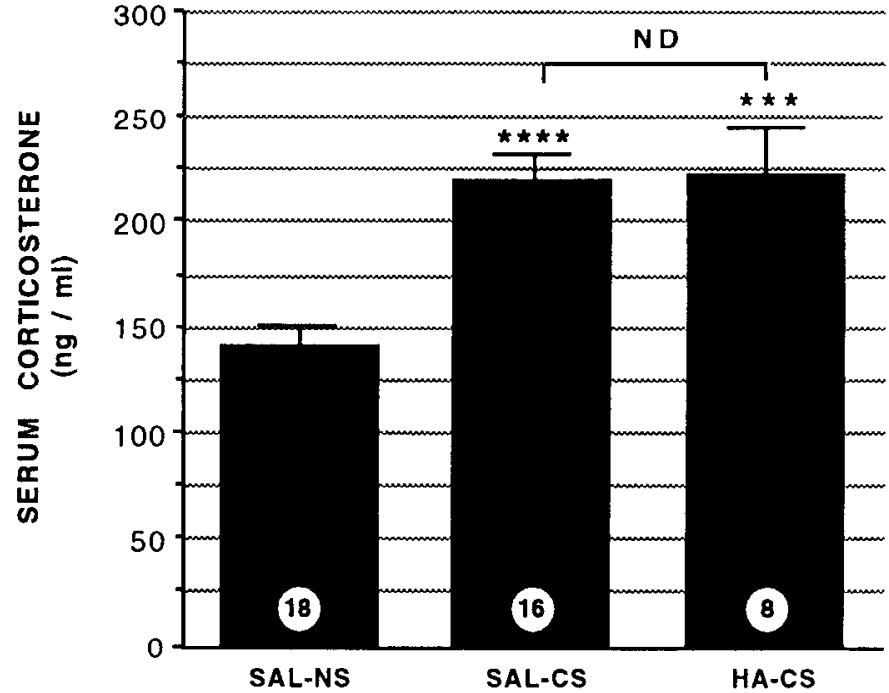

Figure 1. Effect of conditioned stress and (+)-HA-966 pretreatment on serum corticosterone levels in the rat. Rats were pretreated with either saline ( $1 \mathrm{ml} / \mathrm{kg}$, i.p.) or (+)-HA-966 $(15 \mathrm{mg} / \mathrm{kg}$, i.p.) $15 \mathrm{~min}$ before beginning the extinction period on day 2 . Animals were then tested as described in Materials and Methods for $30 \mathrm{~min}$. Data are presented as means $( \pm$ SEM). Numbers in circles at base of histogram bars indicate number of rats in each group. ${ }^{* * * *}$ and $* * *$, significant differences compared to the SAL-NS group control $(p<0.0001$ and $p<0.005$, respectively). $N D$, no significant difference between the SAL-CS and HACS groups.

pretreatment injection to death in the conditioned stress protocol. No difference was detected between saline and (+)-HA966 pretreated rats in DA or 5-HT utilization (Table 2) as measured by the ratio of major metabolite-to-parent neurotransmitter levels in any of the regions tested. Nor was there a difference in basal corticosterone between these groups.

\section{Effect (+)-HA-966 on neuroendocrine and behavioral indices of conditioned stress}

A significant effect of treatment on serum corticosterone was observed $[F(2,39)=13.83, p<0.0001]$ (Fig. 4). Post hoc analysis demonstrated a significant difference in serum corticosterone between shocked and nonshocked saline control groups (SAL-CS, $219.9+12.1 \mathrm{ng} / \mathrm{ml}$; SAI -NS, $140.6+10.2 \mathrm{ng} / \mathrm{ml}$ ) $(p<0.0001)$. This elevation in serum corticosterone in response to conditioned stress was not attenuated by pretreatment with (+)-HA-966 (HA-CS, $222.5+21.5 \mathrm{ng} / \mathrm{ml}$ ).

\section{Table 1. Basal regional concentrations of DA, 5-HT, and their acid metabolites (DOPAC and 5-HIAA) in the naive rat}

\begin{tabular}{lcccccc}
$\begin{array}{l}\text { Region } \\
(n)\end{array}$ & $\begin{array}{l}\text { DOPAC } \\
(\mathrm{ng} / \mathrm{mg} \text { prot) }\end{array}$ & $\begin{array}{l}\text { DA } \\
(\mathrm{ng} / \mathrm{mg} \text { prot) }\end{array}$ & DOPAC:DA & $\begin{array}{l}\text { 5-HIAA } \\
\text { (ng/mg prot) }\end{array}$ & $\begin{array}{l}\text { 5-HT } \\
\text { (ng/mg prot) }\end{array}$ & 5-HIAA:5-HT \\
\hline m-PFC (4) & $0.11 \pm 0.01$ & $0.87 \pm 0.08$ & $0.126 \pm 0.005$ & $24.09 \pm 1.03$ & $76.04 \pm 22.84$ & $0.246 \pm 0.030$ \\
NAC (4) & $17.40 \pm 5.40$ & $132.56 \pm 41.68$ & $0.133 \pm 0.005$ & $12.60 \pm 3.73$ & $28.77 \pm 10.52$ & $0.466 \pm 0.047$ \\
AVM (6) & $44.03 \pm 7.80$ & $509.83 \pm 107.11$ & $0.089 \pm 0.006$ & $56.89 \pm 14.14$ & $109.20 \pm 36.05$ & $0.573 \pm 0.051$ \\
PDL (6) & $40.90 \pm 6.55$ & $495.08 \pm 50.23$ & $0.081 \pm 0.005$ & & \\
LBL (4) & $4.36 \pm 0.41$ & $49.55 \pm 3.78$ & $0.088 \pm 0.006$ & & \\
PR-CX (4) & $0.27 \pm 0.05$ & $2.33 \pm 0.62$ & $0.129 \pm 0.020$ & & \\
CING (4) & $0.33 \pm 0.05$ & $3.29 \pm 1.70$ & $0.158 \pm 0.042$ & & \\
\hline
\end{tabular}

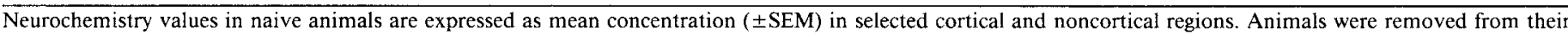

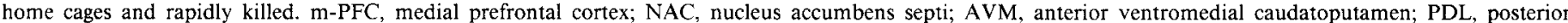

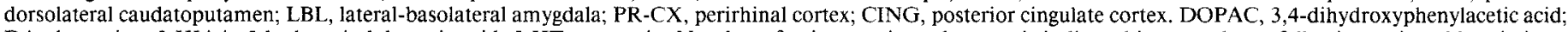

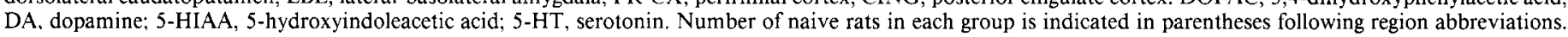


Table 2. Effect of pretreatment with saline or (+)-HA-966 on basal neurochemistry and serum corticosterone

\begin{tabular}{lll} 
& $\begin{array}{l}\text { Saline } \\
\text { pretreatment }\end{array}$ & $\begin{array}{l}(+) \text {-HA-966 } \\
\text { pretreatment }\end{array}$ \\
\hline $\begin{array}{l}\text { Neurochemistry } \\
\text { m-PFC }\end{array}$ & \\
$\quad$ DOPAC:DA & $0.175 \pm 0.022(7)$ & $0.194 \pm 0.018(7)^{\mathrm{ND}}$ \\
5-HIAA:5-HT & $0.291 \pm 0.014(7)$ & $0.340 \pm 0.034(7)^{\mathrm{ND}}$ \\
I-PFC & $0.312 \pm 0.038(5)$ & $0.303 \pm 0.028(6)^{\mathrm{ND}}$ \\
DOPAC:DA & $0.300 \pm 0.031(7)$ & $0.320 \pm 0.028(6)^{\mathrm{ND}}$ \\
5-HIAA:5-HT & $0.146 \pm 0.008(7)$ & $0.130 \pm 0.130(6)^{\mathrm{ND}}$ \\
NAC & $0.530 \pm 0.068(7)$ & $0.572 \pm 0.070(6)^{\mathrm{ND}}$ \\
DOPAC:DA & & $0.116 \pm 0.116(7)^{\mathrm{ND}}$ \\
5-HIAA:5-HT & $0.109 \pm 0.109(7)$ & $114.7 \pm 9.7(7)^{\mathrm{ND}}$ \\
AVM & $119.5 \pm 10.2(7)$ &
\end{tabular}

Systemic pretreatment with (+)-HA-966 at $15 \mathrm{mg} / \mathrm{kg}$ does not alter basal dopamine or serotonin utilization or change basal serum corticosterone levels in control rats. Animals were injected with either saline $(1 \mathrm{ml} / \mathrm{kg}, \mathrm{i} . \mathrm{p})$ or $(+)-\mathrm{HA}-966$ $(15 \mathrm{mg} / \mathrm{kg}$, i.p.) and returned to their home cage in the colony facility for $45 \mathrm{~min}$. This time period corresponds to time from pretreatment injection to death in the conditioned stress protocol. m-PFC, medial prefrontal cortex; 1-PFC, lateral prefrontal cortex; NAC, nucleus accumbens septi; AVM, anterior ventromedial caudatoputamen. Numbers in parentheses indicate number of rats in each group.

ND No significant difference between saline and $(+)$-HA-966 pretreatments.

A significant effect of treatment was also detected for total freezing behavior $[F(2,37)=104.24, p<0.0001]$ (Fig. $5 A$ ). Animals in the SAL-CS group froze more than those in the SAL-NS control group $(\sim<0.0001)$. The SAL-NS group froze $0.99( \pm 0.61) \%$ of the extinction trial while the SAL-CS group froze $72.57( \pm 4.32) \%$ of the time. Pretreatment with $(+)$-HA966 (HA-CS) significantly reduced the percentage of time spent freezing during the extinction trial to 37.49 ( \pm 6.50$) \%$, versus the SAL-CS group $(p<0.0001)$. Thus, pretreatment with $(+)$ HA- 966 resulted in a $48.3 \%$ decrease in conditioned stressinduced freezing.

An ANOVA with repeated measures also revealed a significant interaction between treatment and time $(p<0.0001)$ (Fig. $6 A)$. In the saline pretreated groups, shock on the training day markedly elevated the freezing curve during the extinction trial on the following day $(p<0.0001)$. Pretreatment with $(+)$-HA966 (HA-CS) resulted in a downward shift in the temporal course of freezing during the extinction trial when compared to the saline pretreated conditioned stress group (SAL-CS) $(p<0.0001)$. In the HA-CS group, freezing was reduced during all $3 \mathrm{~min}$ intervals during the extinction trial, except the first. Unlike the SAL-CS group, the HA-CS group was less likely to freeze between tones. During the last $9 \mathrm{~min}$ of the testing period, the HA-CS group froze only $8.4 \pm 3.5 \%$ of the time while the SALCS group froze $56.6 \pm 5.9 \%$ of the time.

Combined horizontal and vertical locomotion (crossings plus rears) was also influenced by treatment $[F(2,37)=59.29, p<$ $0.0001]$ (Fig. 5B). A decrease in locomotion in the SAL-CS group compared to the SAL-NS group was noted $(p<0.0001)$. Mean locomotion scores for the SAL-CS and SAL-NS groups were $50.87( \pm 6.20)$ and $317.06( \pm 25.27)$, respectively. The mean locomotion score for the HA-CS group was $142.89( \pm 14.10)$, a $180.9 \%$ increase over the SAL-CS group ( $p<0.01$ ). In contrast, note that $(+)$-HA-966 pretreatment did not increase spontaneous locomotion in a novel, non-noxious environment (compare Fig. 3).
An ANOVA with repeated mcasures also revealed a significant interaction between treatment and time for locomotion ( $p$ $<0.0001)$. Note the upward shift in the tail of the locomotion curve, which was most evident during the last $9 \mathrm{~min}$ of the extinction trial (Fig. 6B).

\section{Effects of conditioned stress and $(+)-H A-966$ on regional DA utilization}

The results of analyses of DA utilization in cortical, limbic, and striatal regions in response to conditioned stress after injection of either saline or (+)-HA-966 are presented in Figure 7. All data are derived from neurochemical analysis of post mortem brain tissue collected at death immediately following the extinction trial on day 2. DA utilization is expressed as the ratio of the dopamine metabolite DOPAC to the parentage neurotransmitter, DA (i.e., DOPAC:DA). Basal neurochemistry values for naive rats are shown in Table 1.

The only cortical areas that showed a significant effect of treatment on DA utilization were the medial and lateral prefrontal cortices ( $\mathrm{m}-\mathrm{PFC}$ and $\mathrm{l}-\mathrm{PFC}$, respectively). In the $\mathrm{m}-\mathrm{PFC}$, an effect of treatment on DA utilization was observed $[F(2,39)$ $=40.53, p<0.0001]$. The SAL-CS group showed a $96.1 \%$ increase in the DOPAC:DA ratio versus the SAL-NS group ( $p$ $<0.0001)$. Mean DOPAC:DA ratios in the m-PFC for the SALNS and SAL-CS groups were $0.153( \pm 0.013)$ and $0.300( \pm 0.014)$, respectively. This increase in the DOPAC:DA ratio was exclusively due to an increase in the tissue concentration of DOPAC, a pattern noted in the other regions showing increased DOPAC: DA ratios in response to conditioned stress. Significantly, this increase in $\mathrm{M}-\mathrm{PFC}$ DA utilization in the SAL-CS group was completely blocked by pretreatment with (+)-HA-966 ( $p<$ $0.0001)$. Mean DOPAC:DA ratios in the $m-P F C$ for the SAL$C S$ versus $H \wedge-C S$ groups were $0.300( \pm 0.014)$ and 0.160 $( \pm 0.013)$, respectively. There was no difference between the conditioned stress group that had been pretreated with $(+)$-HA966 (HA-CS) and the nonstressed saline pretreated control group 
A

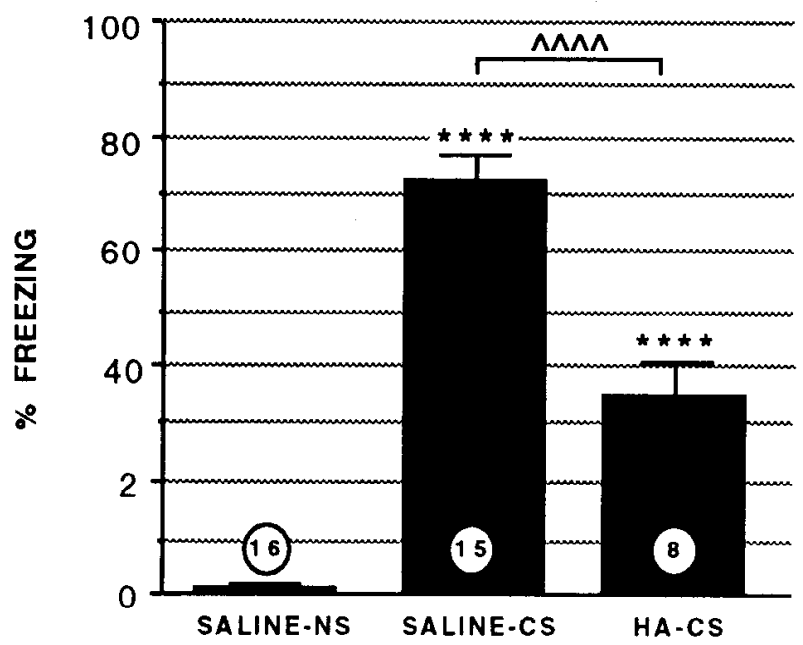

B

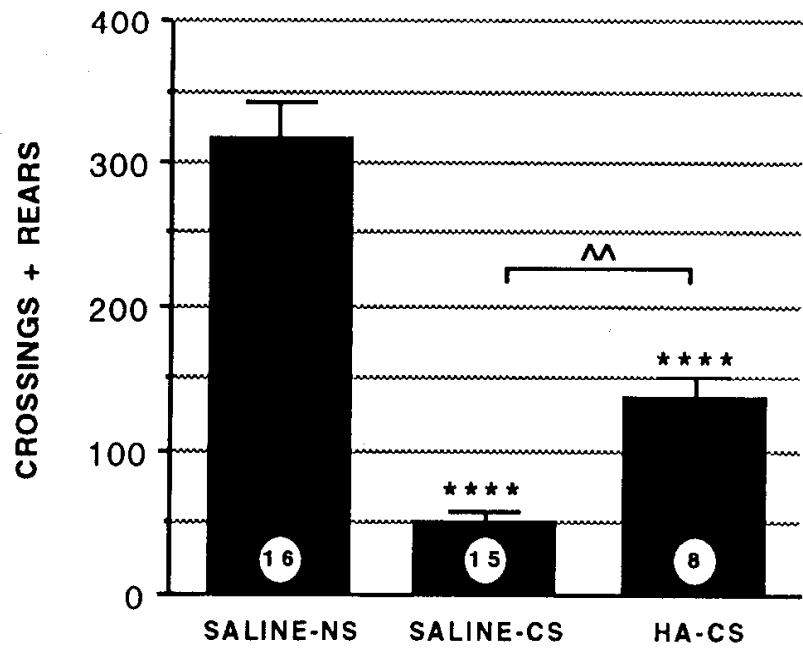

Figure 5. Effect of (+)-HA-966 administration on freezing and locomotor behavior during conditioned stress. Rats were pretreated with saline (1 ml/kg, i.p.) or (+)-HA-966 (15 mg/kg, i.p.) $15 \mathrm{~min}$ before beginning the extinction period on day 2 . A shows effect on freezing behavior. $B$ shows effect on locomotor behavior (crossings and rears). Percentage freezing represents the percentage of total time (in seconds) animals were engaged in this behavior during the $30 \mathrm{~min}$ extinction trial $(1800 \mathrm{sec})$. Crossings + rears indicates number of times the animals crossed hatchings in cage plus the number of rears during the $30 \mathrm{~min}$ extinction trial. Data are presented as means $( \pm$ SEM) for the $30 \mathrm{~min}$ period. Numbers in circles at base of histogram bars indicate number of rats in each group. ${ }^{* * * *}$, significant difference versus the SAL-NS control group $(p<0.0001)$, man, significant difference between the HACS and SAL-CS groups $(p<0.0001)$. ^, significant difference between the HA-CS and SAL-CS groups $(p<0.01)$.

(SAL-NS), suggesting that (+)-HA-966 prevented the regional increase in the DOPAC:DA ratio normally induced by stress.

In the l-PFC, there was also an effect of treatment on DA utilization $[F(2,19)=7.13, p<0.005]$. The SAL-CS group DOPAC:DA ratio nearly doubled in comparison to the SALNS group $(p<0.01)$. Mean DOPAC:DA ratios in the 1-PFC for the SAL-NS and SAL-CS groups were $0.183( \pm 0.023)$ and $0.359( \pm 0.046)$, respectively. This increase in 1-PFC DA utilization in the SAL-CS group was completely blocked by pre-
A

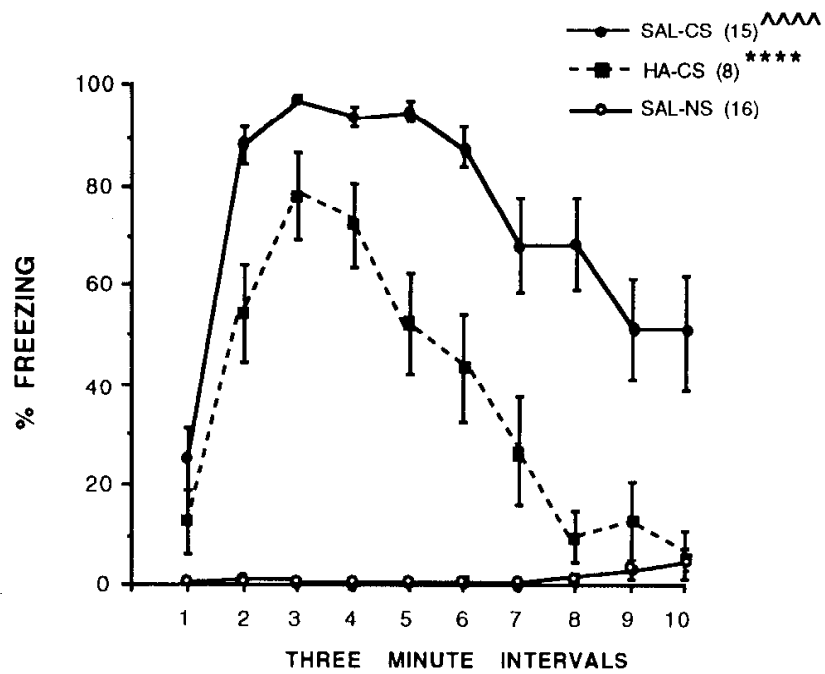

B

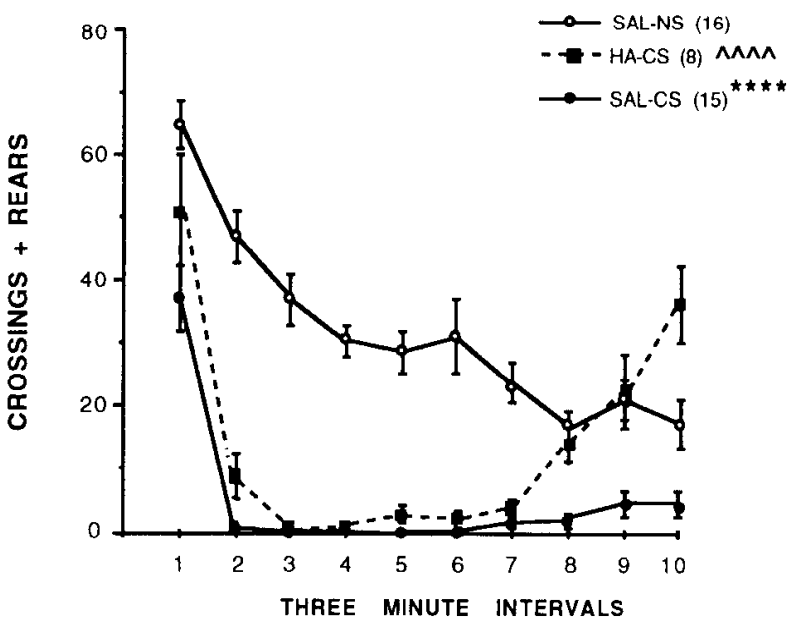

Figure 6. Temporal effect of (+)-HA-966 administration on freezing and locomotor behavior during conditioned stress. Rats were pretreated with salinc ( $1 \mathrm{ml} / \mathrm{kg}$, i.p.) or (+)-IIA-966 (15 mg/kg, i.p.) 15 min befure beginning the extinction period on day 2 . A shows effect on freezing behavior. $B$ shows effect on locomotor behavior (crossings and rears). Percentage freezing represents the percentage of total time (in seconds) animals were engaged in this behavior during each successive $3 \mathrm{~min}$ test interval $(180 \mathrm{sec})$. Crossings + rears indicates number of times the animals crossed hatchings in cage plus the number of rears per $3 \mathrm{~min}$ test interval. Data are presented as means ( \pm SEM) for successive $3 \mathrm{~min}$ intervals. Numbers in circles at base of histogram hars indicate number of rats in each group. ${ }^{* * *}$, significant difference between SAL-NS and SAL-CS groups $(p<0.0001)$. ^^, significant difference between SAL$\mathrm{CS}$ and HA-CS groups $(p<0.0001)$.

treatment with $(+)-\mathrm{HA}-966(p<0.05)$. Mean DOPAC:DA ratios for the SAL-CS versus HA-CS groups were $0.359( \pm 0.046)$ and $0.215( \pm 0.024)$, respectively. No difference in 1-PFC DA utilization between the conditioned stress group pretreated with (+)-HA-966 (HA-CS) and the nonstressed saline pretreated control group (SAL-NS) was observed, suggesting that (+)-HA-966 prevented the regional increase in the DOPAC:DA ratio normally induced by stress. Note that these effects of (+)-HA-966 on stress-induced increases in DA utilization in the $\mathrm{m}-\mathrm{PFC}$ and 1-PFC were not due to (+)-HA-966 lowering basal DA utilization (see Table 2).

DA utilization in the two other cortical regions, the perirhinal and cingulate cortices, was not increased by exposure to con- 


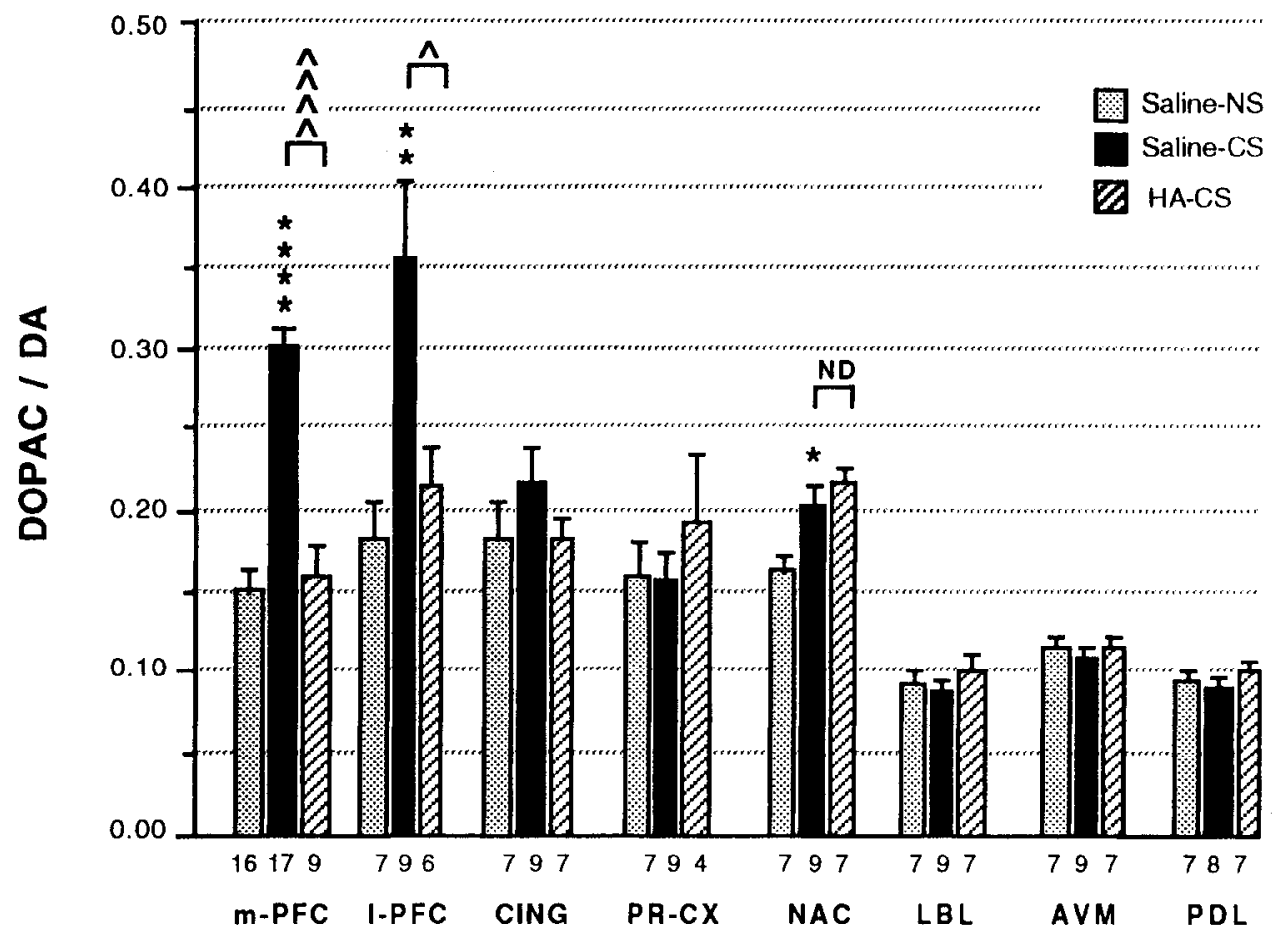

Figure 7. Effect of saline versus $(+,-$ HA-966 pretreatment on dopamine utilization in cortical, limbic, and striatal terminal regions in response to conditioned stress. (+)-HA-966 or saline was administered by intraperitoneal injection at doses of $15 \mathrm{mg} / \mathrm{kg}$ and $1 \mathrm{ml} / \mathrm{kg}$, respectively, $15 \mathrm{~min}$ prior to the extinction trial on day 2. Control animals were subjected to the same training procedures as the conditioned stress groups except that the control group did not receive footshock during the conditioning period. Control animals were also injected with saline (1 ml/kg, i.p.) $15 \mathrm{~min}$ prior to the extinction trial on day 2. Data are expressed as means ( $\pm \mathrm{SEM})$. $m-P F C$, medial prefrontal cortex; $l-P F C$, lateral prefrontal cortex; $C I N G$, posterior cingulate cortex; $P R-C X$, perirhinal cortex; $N A C$, nucleus accumbens septi; $L B L$, lateral-basolateral nuclei of the amygdala; $A V M$, anterior ventromedial caudatoputamen; $P D L$, posterior dorsolateral caudatoputamen. Numbers below histogram bars indicate number of rats in each group. ${ }^{* * * *}$, significant difference between the SAL-NS and SAL-CS groups $(p<0.0001)$. ${ }^{\wedge \mu}$, significant difference between the SAL-CS and HA-CS groups $(p<0.0001){ }^{* *}$, significant difference between the SAL-NS and SAL-CS groups $(p<0.01)$. ^, significant difference between the SAL-CS and HA-CS groups $(p<0.05)$. *, significant difference between the SAL-CS and SAL-NS groups $(p<0.05)$. ND, no significant difference between the SAL-CS and HA-CS groups.

ditioned stress. Nor was there a significant effect of pretreatment with $(+)$-HA-966 in these two cortical regions.

In the NAC, a modest effect of treatment on DA utilization was detected $[F(2,20)=5.01, p<0.05]$. The SAL-CS group showed a $22.9 \%$ increase in the DOPAC:DA ratio versus the SAL-NS group $(p<0.05)$. Mean DOPAC:DA ratios in the NAC for the SAL-NS and SAL-CS groups were $0.166( \pm 0.011)$ and $0.204( \pm 0.013)$, respectively.

In contrast to the effect seen in the $\mathrm{m}-\mathrm{PFC}$ and 1-PFC, this increase in NAC DA utilization in the SAL-CS group was not blocked by pretreatment with (+)-HA-966. Mean DOPAC:DA ratios in the NAC for the SAL-CS versus HA-CS groups were $0.204( \pm 0.013)$ and $0.222( \pm 0.012)$, respectively. A separate control experiment demonstrated that $(+)$-HA-966 administration did not alter the basal DOPAC:DA ratio in this region (see Table 2). In contrast to the effect of stress noted in the NAC, the LBL showed no effect of treatment on DA utilization $[F(2,20)$ $=0.21, p>0.05]$. Mean DOPAC:DA ratios in the LBL for the SAL-NS and SAL-CS groups were $0.106( \pm 0.010)$ and 0.112 $( \pm 0.011)$, respectively. Pretreatment with $(+)$-HA-966 before conditioned stress did not affect DA utilization in this region. Mean DOPAC:DA ratios in the LBL for the SAL-CS versus HA-CS groups were $0.204( \pm 0.013)$ and $0.222( \pm 0.012)$, respectively.

Finally, we examined the effect of conditioned stress on DA utilization in two striatal regions, the anterior ventromedial caudatoputamen (AVM) and the posterior dorsolateral caudatoputamen (PDL). In neither of these two areas was DA utilization affected by treatment. Nor did (+)HA-966 affect DA utilization during conditioned stress. In the AVM, mean DOPAC:DA values for the SAL-NS, SAL-CS, and HA-CS groups were $0.116( \pm 0.006), 0.110( \pm 0.008)$, and $0.117( \pm 0.004)$, respectively. In the PDL, mean DOPAC:DA values for the SALNS, SAL-CS, and HA-CS groups were $0.096( \pm 0.006), 0.091$ $( \pm 0.005)$, and $0.103( \pm 0.007)$, respectively.

\section{Effects of conditioned stress and ( + )-HA-966 on regional 5-IIT utilization}

Results of the effects of conditioned stress and $(+)$-HA-966 pretreatment on 5-ITT utilization are presented in Figure 8. Analyses were conducted on the same animals and tissue samples as those used for the DA studies detailed above. All data are derived from neurochemical analysis of brain tissue collected at death immediately following the extinction trial on day 2 . 5-HT utilization is expressed as the ratio of the 5-HT metabolite 5-hydroxyindoleacetic acid (5-HIAA) to the parent neurotransmitter, 5-HT (i.e., 5-HIAA:5-HT). Basal neurochemistry values for naive rats are shown in Table 1 .

In the m-PFC, an effect of treatment on 5-HT utilization was noted $[F(2,39)=10.29, p<0.001]$. The SAL-CS group showed a $40.6 \%$ increase in the 5-HIAA:5-HT ratio versus the SAL-NS group $(p<0.01)$. Mean 5-HIAA:5-HT ratios in the m-PFC for 
Table 3. Effect of saline or (+)-HA-966 pretreatment 15 min prior to day 1 conditioning

\begin{tabular}{|c|c|c|}
\hline & \multicolumn{2}{|c|}{$\begin{array}{l}\text { Pretraining injection } \\
\text { day } 1\end{array}$} \\
\hline & Saline & (+)-HA-966 \\
\hline \multicolumn{3}{|l|}{ Day 1 responses } \\
\hline Ultrasonic callers & $12 / 17$ & $4 / 9^{N D}$ \\
\hline$\%$ calls $/$ rat & $\begin{array}{l}297.9 \pm 74.4 \\
(17)\end{array}$ & $\begin{array}{l}178.0 \pm 77.9^{\mathrm{ND}} \\
(9)\end{array}$ \\
\hline$\%$ freeze & $\begin{array}{l}53.4 \pm 5.3 \\
(17)\end{array}$ & $\begin{array}{l}45.0 \pm 9.8^{\mathrm{ND}} \\
(9)\end{array}$ \\
\hline \multicolumn{3}{|l|}{ Day 2 responses } \\
\hline$\%$ Freeze & $\begin{array}{l}72.6 \pm 4.3 \\
(15)\end{array}$ & $\begin{array}{l}48.1 \pm 8.9^{*} \\
(9)\end{array}$ \\
\hline $\begin{array}{l}\text { Serum corticosterone } \\
(\mathrm{ng} / \mathrm{ml})\end{array}$ & $\begin{array}{l}219.9 \pm 12.1 \\
(15)\end{array}$ & $\begin{array}{l}222.4 \pm 27.0^{\mathrm{ND}} \\
(9)\end{array}$ \\
\hline DOPAC:DA & $\begin{array}{l}0.300 \pm 0.014 \\
(17)\end{array}$ & $\begin{array}{l}0.238 \pm 0.011^{* *} \\
(9)\end{array}$ \\
\hline \multicolumn{3}{|c|}{$\begin{array}{l}\text { Data show effect of pretreatment with (+)-HA-966 on acquisition of conditioned } \\
\text { stress. Saline or }(+) \text {-HA- } 966 \text { was administered } 15 \text { min prior to the conditioning } \\
\text { period on day } 1 \text {. Data are presented as the mean } \pm \text { SEM with the number of test } \\
\text { subjects in parentheses below. Ultrasonic caller data is presented as the ratio of } \\
\text { callers to all animals in the treated group. The day } 1 \text { responses represent data } \\
\text { collected during the conditioning period on day } 1 \text {. The day } 2 \text { responses represent } \\
\text { data collected from the same rats during the extinction period on day } 2 \text {. Note that } \\
\text { all rats received saline injections before testing on day } 2 \text {. }\end{array}$} \\
\hline $\begin{array}{l}\text { * Significant difference ( } p \\
\text { ** Significant difference ( } p \\
\text { ND No significant difference. }\end{array}$ & & \\
\hline
\end{tabular}

the SAL-NS and SAL-CS groups were $0.246( \pm 0.012)$ and 0.346 $( \pm 0.025)$, respectively. The increase in the ratio of 5-HIAA to $5-\mathrm{HT}$ in the $\mathrm{m}-\mathrm{PFC}$ reflects the composite effects of a decrease in tissue 5-HT and increase in tissuc 5-HIAA. In contrast to findings in the m-PFC DA system, the conditioned stress-induced increase in 5-HT utilization in the m-PFC was not blocked by pretreatment with (+)-HA-966. Mean 5-HIAA:5-HT ratios for the SAL-CS group $(0.346 \pm 0.025)$ were indistinguishable from the HA-CS group $(0.368 \pm 0.018)$.

5-HT utilization was also analyzed in the NAC and the AVM. No effect of treatment on 5-HIAA:5-HT ratios was noted in either region. In the NAC, mean ratios of 5-HIAA:5-HT for the SAL-NS, SAL-CS, and HA-CS groups were $0.582( \pm 0.077)$, $0.786( \pm 0.051)$, and $0.744( \pm 0.069)$, respectively. In the AVM, mean ratios of 5-HIAA:5-HT for the SAL-NS, SAL-CS, and HA-CS groups were $0.481( \pm 0.074), 0.627( \pm 0.048)$, and 0.669 $( \pm 0.021)$.

\section{Effect of pretraining administration of (+)-HA-966 on behavioral, neuroendocrine, and neurochemical indices of conditioned stress}

Since the NMDA receptor complex has been implicated in memory processing, we tested the effect of pretraining administration of (+)-HA-966 on acquisition of the conditioned behavioral, neuroendocrine, and neurochemical responses to conditioned stress (Table 3). Administration of (+)-HA-966 prior to training on day 1 and administration of saline prior to testing on day 2 resulted in attenuation of freezing to the conditioned stimulus $(p<0.05)$. The mean percentage of time engaged in freezing during the extinction trial for saline and (+)-HA-966 pretreated animals was $72.57 \%( \pm 4.31)$ and $48.11 \%( \pm 8.86)$, respectively. Nevertheless, it should be noted that the $(+)-\mathrm{HA}$ -

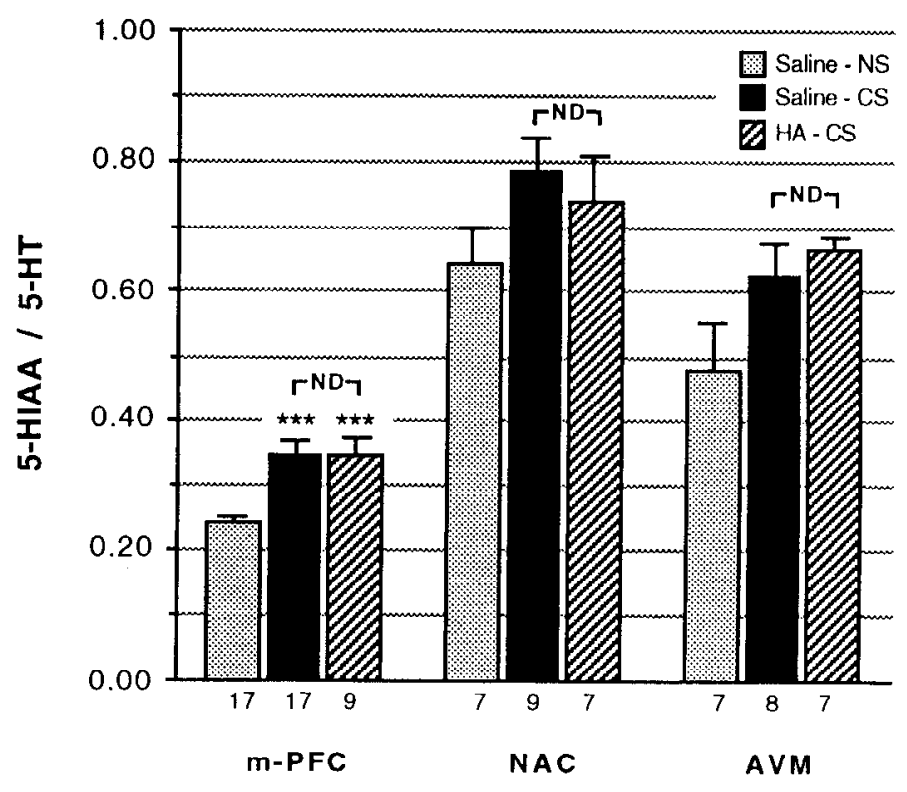

Figure 8. Effect of saline versus $(+)-\mathrm{HA}-966$ pretreatment on 5-HT utilization in the medial prefrontal cortex $\left(m-P F C^{\prime}\right)$, nucleus accumbens $(N A C)$, and anterior ventromedial caudatoputamen $(A V M)$ in response to conditioned stress. Saline or (+)-HA-966 were administered systemically at intraperitoneal doses of $1 \mathrm{~mL} / \mathrm{kg}$ or $15 \mathrm{mg} / \mathrm{kg}$, respectively, 15 min prior to the extinction trial on Day 2. Numbers below histogram bars indicate number of rats in each group. ${ }^{* * *}$, significant difference versus the SAL-NS control group $(p<0.001)$. ND, no significant difference between the SAL-CS and HA-CS groups.

966 pretreated group did exhibit substantial freezing on day 2 , indicating that these animals had learned to fear the conditioned stimulus on the previous day. This is consistent with the observation that serum corticosterone values in the saline and $(+)$ HA-966 pretreated groups were indistinguishable on day 2 . An attenuation in DA utilization in the $\mathrm{m}$-PFC was also observed on day 2 when $(+)$-HA-966 was administered before training on day $1(p<0.01)$.

\section{Discussion}

The present study indicates that pretreatment with (+)-HA-966, an antagonist at the glycine modulatory site of the NMDA receptor complex (Singh et al., 1990), blocks the increase in DA utilization in both the medial and lateral prefrontal cortices in response to conditioned stress. This effect is regionally selective, in that the conditioned stress-induced increase in DA utilization in the nucleus accumbens was not blocked by pretreatment with (+)-HA-966. The effect is neurochemically specific since the conditioned stress-induced increase in 5-HT utilization in the m-PFC was not blocked by pretrcatment with (+)-HA-966. The effect is also state dependent in that (+)-HA-966 caused no changes in basal DA or 5-HT utilization or in serum corticosterone in control rats. This lack of effect on basal neurochemistry stands in contrast to the dose-dependent increases in DA release and metabolism induced by the noncompetitive NMDA receptor antagonist dizocilpine (MK-801; Loscher et al., 1991).

Glycine may be an important endogenous modulator of the NMDA receptor channel complex (Kemp and Leeson, 1993). This hypothesis is supported by in vitro studies that have shown that the response of the NMDA receptor to agonist stimulation is absolutely dependent on the presence of glycine (Kleckner and Dingledine, 1988) and that glycine mediates its actions by 
binding to the NMDA receptor complex (Johnson and Ascher, 1992). Glycine is found in relatively high (micromolar) concentrations in brain extracellular fluid (M. During, personal communication). These data in concert with the present results suggest that the glycine modulatory site of the NMDA receptor complex may play a physiologically significant role in the selective regulation of the mesoprefrontal cortical DA system response to conditioned stress. Furthermore, these data also suggest that endogenous ligands at this site, such as the amino acid glycine and the antagonist kynurenic acid, may be physiological modulators of mesoprefrontal dopaminergic activity.

\section{Effect of $(+)-H A-966$ on behavioral and neuroendocrine responses}

In addition to having effects on prefrontal cortical DA utilization, we observed that (+)-HA-966 pretreatment reduced freezing and increased locomotion in the face of conditioned stress. l'his was manifested as a downward shift in the freezing extinction curve and in early reemergence of locomotion (Fig. 6). Pretrcatmont with (+)-HA-966 attenuated, but did not completely block the behavioral stress response. This finding corroborates and extends recent work by Dunn et al. (1992) suggesting that (+)-HA-966 has anxiolytic behavioral properties.

However, pretreatment with $(+)$-HA-966 prior to conditioned stress did not reduce the stress-induced elevation in serum corticosterone. This is not surprising since (+)-HA-966 pretreated animals still exhibited a substantial, albeit reduced, behavioral stress response. In addition, it should be emphasized that even very large doses of classic anxiolytic agents, such as the benzodiazepine agonist diazepam may only partially suppress the rat adrenocortical response to psychological stress (e.g., Kaneyuki et al., 1991).

\section{Differential responses of dopaminergic and serotonergic systems to conditioned stress}

Unconditioned stress, such as spatial proximity to other rats exposed to footshock (Kaneyuki et al., 1991) or exposure to the urine of stressed conspecifics (Goldstein et al., unpuhlished observations), as well as conditioned stress such as exposure to an environmental context previously paired with footshock (Herman et al., 1982; Deutch et al., 1985), have been shown to increase DA utilization in the m-PFC. Results from the present experiments are in agreement with these previous studies. The present experiments also demonstrate that conditioned stress increases DA utilization in the 1-PFC, but not in the cingulate or perirhinal cortices. This suggests that the different subsets of DA neurons innervating these cortical areas (Lindvall and Bjorklund, 1984) may have different afferent regulatory mechanisms.

A previous study has reported high basal DA utilization in the I-PFC (Jones et al., 1986), a finding corroborated in the present experiments. In one of few other reports cxamining this region, Herman et al. (1982) observed increased DA utilization in response to footshock, but not in response to contextual cues associated with footshock. The present study, however, demonstrates that increased DA utilization in this region does occur in response to conditioned aversive cues. Furthermore, this increase was completely blocked by pretreatment with $(+)$-HA966. The discrepancy between these studies may be accounted for by differences in conditioning protocols. In our experiments, a randomly presented discrete conditioned stimulus (e.g., a substartle-threshold tone) was presented in an overlapping manner with the unconditioned stimulus (e.g., footshock). No such discrete conditioned stimulus was used in the Herman study. We have previously shown in unpublished work that the behavioral, neurohumoral, and neurochemical indices of conditioned stress in our model are under stimulus (i.e., tone) control, suggesting that the presence of this discrete conditioned stimulus may have increased the degree of perceived threat and contributed to the effects on 1-PFC DA utilization seen in the present study. Also, in contrast to the previous study (Herman et al., 1982), the present experiments were conducted during the dark phase of the rat diurnal activity cycle. It is also possible that tissue dissections of the 1-PFC may have differed between studies.

In addition to increasing DA utilization in the prefrontal cortices, conditioned stress was shown to modestly but reliably activate the mesoaccumbens DA system. Exposure to mildly stressful stimuli is known to activate the medial prefrontal cortical DA system selectively whereas more profound or prolonged stimulation from footshock or physical restraint results in recruitment of the mesoaccumbens and finally the mesostriatal DA systems (Roth et al., 1988; Deutch and Roth, 1990). The fact that the mesoaccumbens DA system was activated suggests that the conditioned stress model used in the present study is at least moderately stressful for these animals. It also demonstrates that an increase in DA utilization in the nucleus accumbens is not singularly associated with an increase in locomotion. In addition, dissection of the nucleus accumbens into its core and shell subdivisions reveals that DA utilization in the limbic system-related shell region occurs at levels of stress that do not activate the core (Deutch and Cameron, 1992). The accumbens dissection used in the present study included both core and shell regions, and was similar to that used in previous studies from this laboratory (Roth et al., 1988; Deutch and Roth, 1990) in which the m-PFC was selectively activated by mild stress. Thus, the fact that the mesoaccumbens DA system was only modestly activated by conditioned stress in the present study might reflect a tissue dilution artifact of mesoaccumbens DA activation in the shell subdivision.

Though the effect of various stressors on DA utilization in the $\mathrm{m}-\mathrm{PFC}$ has been known for some time (reviewed by Deutch and Roth, 1990), much less is known about 5-HT utilization in response to stress. The literature on this biogenic amine system and stress is contradictory. In a recent review, Jacobs (1992) concluded that presumptive serotonergic neurons in the raphe nuclei of cats change their firing rate and pattern in response to conditions eliciting arousal, but do not further change their firing frequency or pattern in response to physical stress. Kaneyuki et al. (1991) observed that while exposure of rats to unconditioned psychological stress increased medial prefrontal cortical DA utilization, increased 5-HT utilization was not seen. However, others have demonstrated increases in 5-HT utilization in response to unconditioned physical stress in whole brain (Thierry et al., 1968) and in cortex (Bliss et al., 1968; Adell et al., 1988; Dunn, 1988; Miyauchi et al., 1988; Pei et al., 1990; Heinsbroek et al., 1991). In addition, Inoue and coworkers (1993) observed a selective increase in medial prefrontal cortical 5-HIAA levels in rats reexposed to a context previously paired with intense footshock. This latter study is consistent with our finding that exposure to conditioned stress induces a regionally specific increase in 5-HT utilization in the m-PFC.

We have consistently found this selective increase in medial prefrontal cortical 5-HT utilization in response to conditioned stress to be less substantial, but as reliable as the selective in- 
crease in DA utilization in this region under the same experimental conditions. Differences in results between studies reported in the literature are most likely due to a combination of factors including differences in stress models, duration and intensity of stress exposure, neurochemical endpoints, and means of endpoint measurement. Clearly, further studies of the relationship between regional 5-HT utilization and exposure to conditioned stress are needed.

\section{Effect of $(+)-H A-966$ on conditioned stress-induced increases in mesoprefrontal cortical DA and 5-HT utilization}

The increase in mesoprefrontal cortical DA utilization in response to conditioned stress may be related to alterations in DA neuron firing patterns. DA neurons in the VTA that innervate the prefrontal cortex are known to fire in two different patterns: an irregular mode characterized by spikes frequencies of 3-9 $\mathrm{Hz}$, and a bursting mode in which spikes occur in groups with short interspike intervals (Bunney et al., 1973; Wang, 1981; Grace and Bunney, 1983, 1984). In anesthetized animals, DA neuron bursting is correlated with dramatic increases in DA release in terminal regions. For example, Bean and Roth (1991) have shown that electrical stimulation of the median forebrain bundle in a bursting pattern results in increased DA release in the $\mathrm{m}-\mathrm{PFC}$. In addition, a recent study has demonstrated that pressure ejection of NMDA into the VTA results in burst firing in presumptive DA neurons and enhancement of DA release in the NAC (Suaud-Chagny et al., 1992). These data suggest that the increase in mesoprefrontal cortical DA utilization induced by conditioned stress may be due in part to increased bursting of DA neurons in the VTA with a concomitant increase in DA release and metabolic utilization in stress-activated terminal regions.

That the NMDA receptor complex may be involved in the regulation of DA neurons at the cell body region is supported by several other lines of evidence. NMDA sensitive glutamate binding has been shown to be present in the VTA (Monaghan and Cotman, 1985) and excitatory amino acid afferents to the VTA arise from the cortex (Carter, 1982; Nieoullon and Dustidier, 1983; Christie et al., 1985). Indeed, Sesack and Pickel (1992) have elegantly demonstrated direct monosynaptic input from prefrontal cortical efferents to dopaminergic neurons in the VTA. A recent study has shown that this prefrontal cortical projection to the VTA may be physiologically relevant in that glutamate injection into this cortical region selectively increased burst firing of DA neurons in the VTA and enhanced the release of DA in the NAC, whereas prefrontal cortical injection of the local anesthetic lidocaine resulted in the opposite effects on burst firing and DA release (Murase et al., 1993).

Electrophysiological studies have also shown that NMDA exerts a powerful excitatory effect on midbrain DA neurons in both in vitro and in vivo preparations (Seutin et al., 1990; Mercuri ct al., 1992; Chcrgui ct al., 1993). However, elcctrophysiological investigations to date have not determined whether these findings extend to the DA neurons in the A 10 VTA region that project to the prefrontal cortex. A recent study demonstrated that A9 DA neurons in an in vitro slice preparation change their firing pattern from a regular to bursting mode in response to bath application of NMDA (Johnson et al., 1992). This effect was observed in the presence of the spider venom apamin, a potent antagonist of calcium-dependent potassium channels that is itself known to induce bursting in these neurons (Shepard and Bunney, 1988). An in vivo study in the rat has demonstrated that iontophoretic or pressure injection of the specific NMDA antagonist AP-5 into the A9/A10 DA cell body region regularized cell firing by reducing bursting, whereas injection of NMDAinduced bursting (Chergui el al., 1993). Recent data obtained by Shepard and colleagues demonstrate that modulation of the NMDA receptor at the glycine site exerts a profound effect on A9 DA neuron firing (McMillen et al., 1992; Shepard and Lehmann, 1992). These investigators showed that ( + -HA-966 normalizes the dopaminergic neuron firing pattern such that the variability of intervals between spikes is dramatically reduced.

Kalivas and colleagues (1989) have shown that infusion of NMDA into the VTA selectively increases DA metabolites in the $\mathrm{m}$-PFC. Likewise, direct injection of glutamatc in to the VTA increases DA metabolites in the m-PFC, NAC, and the VTA, while coadministration of the NMDA receptor antagonist CPP selectively blocks the effects of glutamate on m-PFC DA utilization. Similarly, administration of CPP into the VTA prevents footshock-induced increases in DA utilization in the m-PFC. A recent finding from this laboratory has demonstrated that intraVTA infusion of (+)-HA-966 prevents physical restraint-induced increases in m-PFC DA utilization (Morrow et al., 1993). In light of these findings, we hypothesize that $(+)$-HA-966 blocks the increase in mesoprefrontal cortical DA utilization in response to conditioned stress by inhibiting excitatory amino acidinduced excitation of DA cells in the VTA.

Another possible explanation for the ability of $(+)$-HA-966 to block increased DA utilization in the prefrontal cortices during stress invokes interaction of this compound with excitatory amino acid receptors that may regulate $D A$ release at neuronal terminals. A presynaptic excitatory amino acid regulatory mechanism is well established for DA terminals in the striatum (Roberts and Anderson, 1979; Chesselet, 1990). In fact, Crawford and Roberts (1989) demonstrated that a racemic mixture of HA-966 antagonized NMDA-induced enhancement of ${ }^{3} \mathrm{H}-\mathrm{DA}$ release from rat striatal slices. This antagonism was reversed by inclusion of glycine in the bathing solution. A similar, though speculative, mechanism operating at the DA terminals in the cortex could explain the present results. Even though excitatory amino acid presynaptic regulation of DA release in the $\mathrm{m}-\mathrm{PFC}$ has not been demonstrated, Moghaddam et al. (1993) have shown that glutamate and aspartate levels in the m-PFC increase in response to restraint and swim stress.

In contrast to its effect on DA utilization in the prefrontal cortices during conditioned stress, $(+)$-HA-966 does not block the conditioned stress-induced increase in medial prefrontal cortical 5-HT utilization. This finding clearly points to the neurochemical specificity of the effects of $(+)$-HA-966. Furthermore, these data indicate that the afferent control of the activation of the mesoprefrontal cortical serotonergic system probably does not involve glycine-modulated NMDA receptor mediated mechanisms.

\section{Effect of $(+)-H A-966$ on acquisition of conditioned aversive memory}

The NMDA receptor complex has been implicated in memory processing events (e.g., Morris et al., 1986; Miserendino et al., 1990). A recent report indicates that the NMDA glycine site may also be involved in memory processing since the NMDA glycine site agonist D-cycloserine appears to facilitate retention of an avoidance task in mice (Flood et al., 1992). These studies have suggested that $(+)$-HA-966 might impair memory. However, in the present study, rats pretreated with $(+)$-HA-966 prior 
to conditioning demonstrated elevations in serum corticosterone, freezing, and $\mathrm{m}$-PFC DA utilization in response to the conditioned stimuli, demonstrating that the animals had indeed learned to associate the tone with footshock. This finding in dicates that $(+)-\mathrm{HA}-966$, at a dose of $15 \mathrm{mg} / \mathrm{kg}$, does not block aversive memory formation under these experimental conditions.

Nevertheless, at least two components of the stress response, freezing and increased $\mathrm{m}$-PFC DA utilization, were attenuated under this regimen indicating that (1) the perception of and/or reaction to the unconditioned stimulus was blunted at the time of the conditioning, consistent with the hypothesis that $(+)-$ HA-966 exhibits anxiolytic properties (Dunn et al, 1992), and/ or (2) the conditioned aversive memories were rendered less stable during memory acquisition or consolidation, consistent with this compound's known ability to alter NMDA receptor function at the glycine modulatory site. In addition, we cannot rule out the possibility that the effects of preconditioning administration of (+)-HA-966 on behavioral and neurochemical indices measured the following day may reflect prolonged pharmacokinetic clearance of (+)-HA-966 or the persistence of bioactive metabolites. However, the finding that pretraining treatment with this compound alters behavioral and neurochemical expression of conditioned stress without blocking formation of aversive memories suggests that (+)-HA-966 administered at this dose may differentially affect processes that are influenced by NMDA receptor systems. Further work is necessary to clarify these issues.

\section{Clinical relevance and possible therapeutic potential of $(+)$ - HA-966}

Both in vitro and in vivo studies have demonstrated that DA and 5-HT influence cortical electrophysiological activity (Bunney and Aghajanian, 1976; Mantz et al., 1988, 1990; Sesack and Bunney, 1989; Gellman and Aghajanian, 1993). Thus, catecholamines may contribute to cognition, possibly by enhancing signal processing in the cortex (Servan-Schreiber et al., 1991). Studies in the rat have demonstrated cognitive impairment following destruction of the A10 DA neurons that project to the m-PFC (Simon et al., 1980). Cortical DA depletion in the dorsolateral prefrontal cortex of rhesus monkeys is associated with cognitive deficits that are reversed by administration of the DA precursor L-dopa or the DA agonist apomorphine (Brozoski, 1979). In addition, direct injection of a DA antagonist into the prefrontal cortex of rhesus monkeys induces specific cognitive deficits related to working memory (Sawaguchi and GoldmanRakic, 1991).

One of the hallmarks of schizophrenia is alteration in formal thought processes and cognition. Though the neuropathology of this disorder is unclear, cortical dysfunction in this disorder has been related to dopaminergic dysregulation (Weinberger et al., 1986; Davis et al., 1992). In addition, certain symptoms of this disorder are thought to be induced or exacerbated by stress (Zubin and Spring, 1977; Brown and Birley, 1968; Bebbington et al., 1993). The fact that (+)-HA-966 blocks the conditioned stress-induced activation of the m-PFC DA system at a nonsedating dose without altering basal dopaminergic metabolic activity suggests the possibility that this drug may be a novel pharmacological agent for the treatment of schizophrenia.

Post-traumatic stress disorder (PTSD) is a psychiatric disorder caused by exposure to overwhelmingly stressful circumstances. Inescapable footshock and conditioned fear in animals have been suggested as models of this anxiety disorder (van der Kolk et al., 1985; Charney et al., 1993). In PTSD, cues associated with an initial trauma later become capable of eliciting a psychological and physiological reaction similar to that induced by the initial trauma. Thus, the finding that $(+)-\mathrm{HA}-966$ appears to hasten the rate of extinction of defensive responses to conditioned stressful stimuli suggests that this drug may also be useful in the treatment of PTSD. Furthermore, the finding that (+)-HA-966 does not block acquisition of aversive memories, but mitigates the neurochemical and behavioral responses to these memories, suggests that administration of this drug may be relatively free of unwanted cognitive side effects.

Further electrophysiological, neurochemical, and behavioral studies are clearly necessary to elucidate the means by which (+)-HA-966 modulates stress activation of the mesoprefrontal cortical DA system. This future work may help clarify the possible contribution of the mesoprefrontal cortical DA system and the NMDA receptor complex to the pathophysiology and therapeutic management of stress-induced or stress-exacerbated neuropsychiatric disorders.

\section{References}

Abcrcrombic ED, Kcefc KA, DiFrischia DF, Zigmond MJ (1989) Differential effects of stress on in vivo dopamine release in striatum, nucleus accumbens, and medial prefrontal cortex. J Neurochem 52 : 1655-1658.

Adell A, Trullas R, Gelpi E (1988) Time course of changes in serotonin and noradrenaline in rat brain after predictable or unpredictable shock. Brain Res 459:54-59.

Bean AJ, Roth RH (1991) Extracellular dopamine and neurotensin in rat prefrontal cortex in vivo: effects of median forebrain bundle stimulation frequency, stimulation pattern, and dopamine autoreceptors. J Neurosci 11:2694-2702.

Bebbington P, Wilkins S, Jones P, Foerster A, Murray R, Toone B, Lewis S (1993) Life events and psychosis: initial results from the Camberwell Collaborative Psychosis Study. Br J Psychiatry 162:7279.

Blanchard RJ, Blanchard DC (1969) Crouching as an index of fear. J Comp Physiol Psychol 67:370-375.

Bliss EL, Ailion J, Zwanziger J (1968) Metabolism of norepinephrine, serotonin, and dopamine in rat brain with stress. J Pharmacol Exp Ther 164:122-134.

Bouton ME, Bolles RC (1980) Conditioned fear as assessed by freezing and by the suppression of three different baselines. Animal Learn Behav 8:429-434

Bristow DR, Bowery NG, Woodruff GN (1986) Light microscopic autoradiographic localization of $\left[{ }^{3} \mathrm{H}\right]$-glycine and $\left[{ }^{3} \mathrm{H}\right]$-strychnine binding sites in the rat brain. Eur J Pharmacol 126:303-308.

Brown GW, Birley JLT (1968) Crises and life changes and the onset of schizophrenia. J Health Social Behav 9:203-214.

Brozoski TJ, Brown RM, Rosvold HE, Goldman PS (1979) Cognitive deficit caused by regional depletion of dopamine in prefrontal cortex of rhesus monkey. Science 205:929-932.

Bunney BS, Aghajanian GK (1976) Dopamine and norepinephrine innervated cells in the rat prefrontal cortex: pharmacological differentiation using microiontophoretic techniques. Life Sci 19:1783-1792.

Bunney BS, Walters JR, Roth RH, Aghajanian GK (1973) Dopaminergic neurons: effect of antipsychotic drugs and amphetamine on single cell activity. J Pharmacol Exp Ther 185:560-571.

Carter CJ (1982) Topographical distribution of possible glutamatergic pathways from the frontal cortex to the striatum and substantia nigra in rats. Neuropharmacology 21:378-383.

Charney DS, Deutch AY, Krystal JH, Southwick SM, Davis MD (1993) Psychobiologic mechanisms of posttraumatic stress disorder. Arch Gen Psychiatry 50:294-305.

Chergui K, Charlety PJ, Akaoka H, Saunier CF, Brunet J-L, Buda M, Svensson TH, Chouvet G (1993) Tonic activation of NMDA receptors causes spontaneous burst discharge of rat midbrain dopamine neurons in vivo. Eur J Neurosci 5:137-144. 
Chesselet M-F (1990) Presynaptic regulation of dopamine release: implications for the functional organization of the basal ganglia. Ann NY Acad Sci 604:17-22.

Christie MJS, Bridge LB, Beart PM (1985) Excitotoxin lesions suggest an aspartatergic projection from rat medial prefrontal cortex to ventral tegmental area. Brain Res 333:169-172.

Collingridge GL, I ester RAJ (1989) Fxcitatory amino acid recentors in the vertebrate central nervous system. Pharmacol Rev 40:143-210.

Conti LH, Naeiver CR, Ferkany JW, Abreau ME (1990) Footshockinduced freezing behavior in rats as a model for assessing anxiolytics. Psychopharmacology 102:492-497.

Crawford M, Roberts PJ (1989) 1-Hydroxy-3-aminopyrrolid-2-one (HA-966) and kynurenate antagonize $N$-methyl-D-aspartate induced enhancement of $\left[{ }^{3} \mathrm{H}\right]$-dopamine release from rat striatal slices. Biochem Pharmacol 23:4165-4168.

Davis KL, Kahn RS, Ko G, Davidson M (1991) Dopamine in schizophrenia: a review and reconceptualization. Am J Psychiatry 148: $1474-1486$.

Deutch AY, Cameron DS (1992) Pharmacological characterization of the dopamine system in the nucleus accumbens core and shell. Neuroscience 46:49-56.

Deutch AY, Roth RH (1990) The determinants of stress-induced activation of the prefrontal cortical dopamine system. In: The prefrontal cortex: its structure, function and pathology (Vylings HBM, Van Eden CG, DeBruim JPC, Corner MA, Feenstra MPG, eds), pp 357-393. Amsterdam: Elsevier.

Deutch AY, Tam S-Y, Roth RH (1985) Footshock and conditioned stress increase 3,4-dihydroxyphenylacetic acid (DOPAC) in the ventral tegmental area but not substantia nigra. Brain Res 333:143-146.

Dunn AJ (1988) Stress-related changes in cerebral catecholamine and indoleamine metabolism: lack of effect of adrenalectomy and corticosterone. J Neurochem 51:406-412.

Dunn AJ, Welch J (1991) Stress- and endotoxin-induced increases in brain tryptophan and serotonin metabolism depend on sympathetic nervous system activity. J Neurochem 57:1615-1622.

Dunn RW, Flanagan DM, Martin LL, Kerman LL, Woods AT, Camacho F, Wilmot CA, Cornfeldt ML, Effland RC, Wood PL, Corbett R (1992) Stereoselective $R(+)$ enantiomer of HA-966 displays anxiolytic effects in rodents. Eur J Pharmacol 214:207-214.

Fanselow MS (1980) Conditional and unconditional components of post-shock freezing. J Biol Sci 15:177-182.

Fanselow MS (1984) What is conditioned fear? Trends Neurosci 7:460462.

Flood JF, Morley JE, Lanthorn TH (1992) Effect on memory processing by D-cycloserine, an agonist of the NMDA/glycine receptor. Eur J Pharmacol 221:249-254.

Fokkema DS, Koolhaas JM, van der Muelen J, Schoemaker R (1986) Social stress-induced pressure breathing and consequent blood pressure oscillation. Life Sci 38:569-575.

Frysztak RJ, Neafsey EJ (1991) The effect of medial prefrontal cortex lesions on respiration, freezing, and ultrasonic vocalizations during conditioned emotional responses in rats. Cereb Cortex 1:418-425.

Gellman RL, Aghajanian GK (1993) Pyramidal cells in the piriform cortex receive a convergence of inputs from monoamine activated GABAergic interneurons. Brain Res 600:63-73.

Grace AA, Bunney BS (1983) Intracellular and extracellular electrophysiology of nigral dopaminergic neurons. I. Identification and characterization. Neuroscience 24:19-28.

Grace AA, Bunney BS (1984) The control of firing pattern in nigral dopamine neurons: burst firing. J Ncurosci 4:2877-2890.

Heinsbroek RPW, Van Haaven F, Fecustra MGP, Boon P, Van der Poll NE (1991) Controllable and uncontrollable footshock and monoaminergic activity in the frontal cortex of male and female rats. Brain Res 551:247-255.

Herman IP, Guillonneau D, Dantzer R, Scatton B, Semerdjian-Rouguier L, LeMoal M (1982) Differential effects of inescapable footshocks and of stimuli previously paired with inescapable footshocks on dopamine turnover in cortical and limbic areas of the rat. Life Sci 30:2207-2214.

Inoue T, Koyama T, Yamashita I (1993) Effect of conditioned fear stress on serotonin metabolism in the rat brain. Pharmacol Biochem Behav 44:371-374.

Jacobs BL, Fornal CA (1991) Activity of brain serotonergic neurons in the behaving animal. Pharmacol Rev 43:563-578.

Johnson JW, Ascher P (1992) Equilibrium and kinetic study of glycine action on the $N$-methyl-D-aspartate receptor in cultured mouse brain neurons. J Physiol (Lond) 455:339-365.

Johnson SW, Seutin V, North RA (1992) Burst firing in dopamine neurons induced by $N$-methyl-D-aspartate: role of electrogenic sodium pump. Science 258:665-667.

Jones MW, Kilpatrick IC, Phillipson OT (1986) The agranular insular cortex: a site of unusually high dopamine utilization. Neurosci Lett 72:330-334.

Kalivas PW (1993) Neurotransmitter regulation of dopamine neurons in the ventral tegmental area. Brain Res Rev 18:75-113.

Kalivas PW, Duffy P, Barrow J (1989) Regulation of the mesocorticolimbic dopamine system by glutamic acid receptor subtypes. J Pharmacol Exp Ther 251:378-387.

Kaneyuki H, Yokoo H, Tsuda A, Yoshida M, Mizuki Y, Yamada M, Tanaka M (1991) Psychological stress increases dopamine turnover selectively in mesoprefrontal dopamine neurons of rats: reversal by diazepam. Brain Res 557:154-161.

Kemp JA, Leeson PD (1993) The glycine site of the NMDA receptorfive years on. Trends Pharmacol Sci 14:20-25.

Kleckner NW, Dingledine R (1988) Requirement for glycine in activation of NMDA receptors expressed in Xenopus oocytes. Science 241:835-837.

Lindvall O, Bjorklund A (1984) General organization of cortical monoamine systems. In: Monoamine innervation of the cerebral cortex (Descarries L, Reader TR, Jasper HH, eds), pp 9-40. New York: Liss.

Loscher W, Annies R, Honack D (1991) The $N$-methyl-D-aspartate receptor antagonist MK-801 induces increases in dopamine and serotonin metabolism in several brain regions of rats. Neurosci Lett 128:191-194.

Lowry OH, Rosebrough JJ, Farr AL, Randall RJ (1951) Protein measurement with the folin reagent. J Biol Chem 193:265-275.

Maas JW, Dekirmenjian H, Fawcett J (1971) Catecholamine metabolism, depression and stress. Nature 230:330-331.

Mantz J, Milla C, Glowinski J. Thierry AM (1988) Differential effects of ascending neurons containing dopamine and noradrenaline in the control of spontaneous activity and of evoked responses in the rat prefrontal cortex. Neuroscience 27:517-526.

Mantz J, Godbout R, Tassin J-P, Glowinski J, Thierry AM (1990) Inhibition of spontaneous and evoked unit activity in the rat medial prefrontal cortex by mesencephalic raphe nuclei. Brain Res 524:2230 .

McMillen BD, Williams HL, Lehmann H, Shepard PD (1992) On central muscle relaxants, strychnine-insensitive glycine receptors and two old drugs: zoxazolamine and HA-966. J Neural Transm 89:1125.

Mercuri NB, Stratta F, Calabresi P, Bernardi G (1992) A voltageclamp analysis of NMDA-induced responses on dopaminergic neurons of the rat substantia nigra zona compacta and ventral tegmental area. Brain Res 593:51.

Miserendino MJD, Sananes CB, Melia KR, Davis M (1990) Blocking of acquisition but not expression of conditioned fear-potentiated startle by NMDA antagonists in the amygdala. Nature 345:716-718.

Miyauchi T, Dworkin Sl, Smith JE (1988) Specific effects of punishment on biogenic monoamine turnover in discrete rat brain regions. Brain Res 454:40-50.

Moghaddam B (1993) Stress preferentially increases extraneuronal levels of excitatory amino acids in the prefrontal cortex: comparison to hippocampus and basal ganglia. J Neurochem 60:1650-1657.

Monaghan DT, Cotman CW (1985) Distribution of $N$-methyl-D-aspartate sensitive $\mathrm{L}_{-}\left[{ }^{3} \mathrm{H}\right]$-glutamate binding sites in rat brain. J Neurosci 5:2909-2919.

Morris ROM, Anderson E, Lynch GS, Baudry SM (1986) Selective impairment of learning and blockage of long-term potentiation by an $N$-methyl-D-aspartate receptor antagonist, AP5. Nature 319:774.

Morrow BA, Clark WA, Roth RH (1993) Stress activation of mesocorticolimbic dopamine neurons: effects of a glycine/NMDA receptor antagonist. Eur J Pharmacol 238:255-262.

Murase S, Grenhoff J, Chouvet G, Gonon FG, Svensson TH (1993) Prefrontal cortex regulates burst firing and transmitter release in rat mesolimbic dopamine neurons studied in vivo. Neurosci Lett 157: 53-56.

Nieoullon A, Dustidier N (1983) Glutamate uptake, glutamate decarboxylase and choline acetyltransferase in subcortical areas after sensorimotor cortical ablations in the cat. Brain Res Bull 10:287293. 
Pei Q, Zetterstrom T, Fillenz M (1990) Tail pinch-induced changes in the turnover and release of dopamine and 5-hydroxytryptamine in different brain regions of the rat. Neurosci 35:133-138.

Reinhard JF Jr, Roth RH (1982) Noradrenergic modulation of serotonin synthesis and metabolism. I. Inhibition by clonidine in vivo. $\mathbf{J}$ Pharmacol Exp Ther 221:541-546.

Roberts PJ, Anderson SD (1979) Stimulatory effect of L-glutamate and related amino acids on [ $\left.{ }^{3} \mathrm{H}\right]$-dopamine release from rat striatum: an in vitro model for glutamate actions. J Neurochem 32:1539-1545.

Roth RH, Tam SY, Ida Y, Yang JX, Deutch AY (1988) Stress and the mesocorticolimbic dopamine systems. Ann NY Acad Sci 537: 138-147.

Rubin RT, Miller RG, Clark BR, Poland RE, Arthur RJ (1970) The stress of aircraft carrier landings. II. 3-methoxy-4-hydroxyphenylglycol excretion in naval aviators. Psychosom Med 32:589-597.

Sawaguchi T, Goldman-Rakic PS (1991) Dl dopamine receptors in prefrontal cortex: involvement in working memory. Science 251:947950.

Servan-Schreiber D, Printz H, Cohen JD (1990) A network model of catecholamine effects: gain, signal-to-noise ratio, and behavior. Science 249:892-895.

Sesack SR, Bunney BS (1989) Pharmacological characterization of the receptor mediating electrophysiological responses to dopamine in the rat medial prefrontal cortex: a microiontophoretic study. J Pharmacol Exp Ther 248:1323-1333.

Sesack SR, Pickel VM (1992) Prefrontal cortical efferents in the rat synapse on unlabeled neuronal targets of catecholamine terminals in the nucleus accumbens septi and on dopamine neurons in the ventral tegmental area. J Comp Neurol 320:145-160.

Seutin V, Verbanck P, Massotte L, Dresse A (1990) Evidence for the presence of $N$-methyl-D-aspartate receptors in the ventral tegmental area of the rat: an electrophysiological in vitro study. Brain Res 514 $147-150$

Sewell GD (1967) Ultrasound in adult rodents. Nature 215:512.

Shepard PD, Bunney BS (1988) Effects of apamin on the discharge properties of putative dopamine-containing neurons in vitro. Brain Res 463:380-384
Shepard PD, Lehmann H (1992) (+)-1-Hydroxy-3-aminopyrrolidone-2 (HA966) inhibits the activity of nigral dopamine-containing neurons through a non-NMDA receptor-mediated mechanism. J Pharmacol Exp Ther 261:387-394.

Simon HB, Scatton B, LeMoal M (1980) Dopaminergic A10 neurons are involved in cognitive functions. Nature 286:150-151.

Singh L, Donald AE, Foster AC, Hutson PH, Iversen LL, Iversen SD, Kemp JA, Leeson PD, Marshall GR, Oles RJ, Priestley T, Thorn L, Tricklebank MD, Vass CA, Williams BJ (1990) Enantiomers of HA-966 (3-amino-1-hydroxypyrrolid-2-one) exhibit distinct central nervous systems effects: $(+)$-HA-966 is a selective glycine/ $N$-methyl$\mathrm{D}$-aspartate receptor antagonist, but (-)-HA-966 is a potent gammabutyrolactone-like sedative. Proc Natl Acad Sci USA 87:347-351.

Sorg BA, Kalivas PW (1993) Effects of cocaine and footshock stress on extracellular dopamine levels in the medial prefrontal cortex. Neuroscience 53:695-703.

Suaud-Chagny MF, Chergui K, Chouvet G, Gonon F (1992) Relationship between dopamine release in the rat nucleus accumbens and the discharge activity of dopaminergic neurons during local in vivo application of amino acids in the ventral tegmental area. Neuroscience 49:63-72

Thierry A-M, Fekete M, Glowinski J (1968) Effects of stress on the metabolism of noradrenaline, dopamine, and serotonin in the central nervous system of the rat. II. Modifications of serotonin metabolism. Eur J Pharmacol 4:384-389.

Thierry AM, Tassin JP, Blanc G, Glowinski J (1976) Selective activation of the mesocortical DA system by stress. Nature 263:242-244.

van der Kolk B, Greenberg M, Boyd H, Krystal J (1985) Inescapable shock, neurotransmitters, and addiction to trauma: toward a psychobiology of posttraumatic stress. Biol Psychiatry 20:314-325.

Wang RY (1981) Dopaminergic neurons in the rat ventral tegmental area. I. Identification and characterization. Brain Res Rev 3:1 23-140.

Weinberger DR, Berman KF, Zee RF (1986) Physiological dysfunction of dorsolateral prefrontal cortex in schizophrenia. I. Regional cerebral blood flow (rCBF) evidence. Arch Gen Psychiatry 43:114-125.

Zubin J, Spring B (1977) Vulnerability-a new view of schizophrenia J Abnormal Psychol 86:103-126. 